\title{
ARTICLE OPEN \\ Destabilization of linker histone H1.2 is essential for ATM activation and DNA damage repair
}

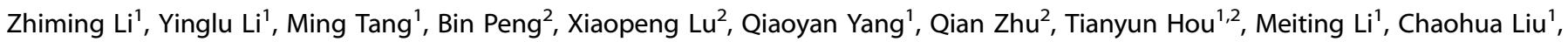
Lina Wang ${ }^{1}$, Xingzhi $\mathrm{Xu}^{2}$, Ying Zhao ${ }^{1}$, Haiying Wang ${ }^{1}$, Yang Yang ${ }^{1}$ and Wei-Guo Zhu $\mathbb{D}^{1,2}$

Linker histone $\mathrm{H} 1$ is a master regulator of higher order chromatin structure, but its involvement in the DNA damage response and repair is unclear. Here, we report that linker histone $\mathrm{H} 1.2$ is an essential regulator of ataxia telangiectasia mutated (ATM) activation. We show that $\mathrm{H} 1.2$ protects chromatin from aberrant ATM activation through direct interaction with the ATM HEAT repeat domain and inhibition of MRE11-RAD50-NBS1 (MRN) complex-dependent ATM recruitment. Upon DNA damage, H1.2 undergoes rapid PARP1-dependent chromatin dissociation through poly-ADP-ribosylation (PARylation) of its $C$ terminus and further proteasomal degradation. Inhibition of H1.2 displacement by PARP1 depletion or an H1.2 PARylation-dead mutation compromises ATM activation and DNA damage repair, thus leading to impaired cell survival. Taken together, our findings suggest that linker histone $\mathrm{H} 1.2$ functions as a physiological barrier for ATM to target the chromatin, and PARylation-mediated active H1.2 turnover is required for robust ATM activation and DNA damage repair.

Cell Research (2018) 28:756-770; https://doi.org/10.1038/s41422-018-0048-0

\section{INTRODUCTION}

The nucleosome, as a basic unit of chromatin, is composed of an octamer of core histones associated with about $146 \mathrm{bp}$ of DNA. Linker histone $\mathrm{H} 1$ serves as an intranucleosomal architectural protein that unlike the relatively stable organization of core histones, is dynamically bound to chromatin to regulate chromatin accessibility and plasticity. ${ }^{1,2} \mathrm{H} 1$ has some 11 isoforms in mammalian cells, which redundantly regulate higher order chromatin structure. Although isoform-specific deletion of $\mathrm{H} 1$ has no detectable phenotypes in protozoans or mice, ${ }^{3,4}$ the combined depletion of three isoforms in mouse embryonic stem (ES) cells leads to profound chromatin structural defects. ${ }^{5}$ Deletion of $\mathrm{H} 1$ in Drosophila leads to high frequency of sister-chromatid exchanges and DNA breaks, ${ }^{6}$ indicating that $\mathrm{H} 1$ is a critical regulator of genome stability and integrity.

In addition to its role in controlling chromatin structure, there is accumulating evidence that $\mathrm{H} 1$ also participates in the regulation of the DNA damage response and repair, but its precise role remains controversial. In yeast, depletion of $\mathrm{H} 1$ up-regulates the homologous recombination (HR) repair machinery and increases resistance to DNA damage. ${ }^{7}$ In addition, mouse ES cells with reduced $\mathrm{H} 1$ levels show increased DNA damage signaling and hyper-resistance to DNA-damaging agents. ${ }^{8}$ Others have reported that $\mathrm{H} 1$ amplifies ubiquitin signals in the DNA damage response, whereby RNF8 coordinates with RNF168 to promote the recruitment of downstream proteins, thus facilitating DNA repair. ${ }^{9} \mathrm{H} 1$ also enhances the backup non-homologous end-joining (NHEJ) pathway by stimulating the activities of DNA ligase IV and III. $^{10}$
Nevertheless, the exact mechanisms underlying the role of $\mathrm{H} 1$ in the DNA damage response and repair need to be further elucidated. As one of the most abundant $\mathrm{H} 1$ variants, linker histone $\mathrm{H} 1.2$ is unique among its family members as it specifically regulates DNA damage-induced apoptosis. Moreover, deletion of $\mathrm{H} 1.2$ has been shown to render cancer cells or mice resistant to DNA damaging agents. ${ }^{11}$ In addition, H1.2 shows a distinct preference for AT-rich DNA regions, which tend to be more fragile upon DNA damage due to weaker hydrogen bonds, while other $\mathrm{H} 1$ isoforms prefer to bind to GC-rich regions. ${ }^{12}$ These data raise the possibility that $\mathrm{H} 1.2$ may have specific roles in regulating the DNA damage response and repair.

Ataxia telangiectasia mutated (ATM) is a master kinase involved in the DNA damage response and repair, which exists as an inactive homodimer or higher order multimer under basal conditions. ${ }^{13}$ Activation of ATM is a complex and tightly regulated process that requires exposure of DNA breaks, a cascade of acetylation and phosphorylation, and the assembly of the MRE11RAD50-NBS1 (MRN) complex. ${ }^{13-18}$ Numerous cellular processes have been implicated in ATM activation and signaling, including PARP1-mediated poly-ADP-ribosylation (PARylation) during DNA damage. $^{19}$ ATM activation may be associated with structural changes to chromatin as the induction of perturbations to chromatin using sodium chloride $(\mathrm{NaCl})$, chloroquine $(\mathrm{CHQ})$ or histone deacetylase (HDAC) inhibitors can potently activate ATM without eliciting DNA damage. ${ }^{13}$ Chromatin interactions modulated by the nucleosome-binding protein HMGN1 through the regulation of histone acetylation are also essential for ATM

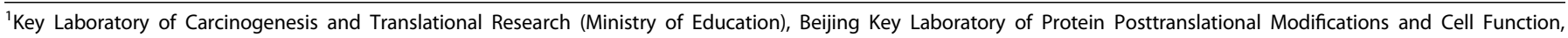

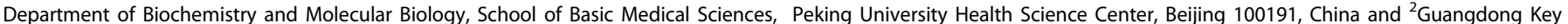

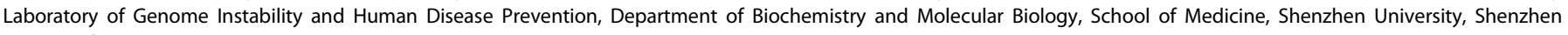
518060, China

Correspondence: Wei-Guo Zhu (zhuweiguo@szu.edu.cn)

These authors contributed equally: Zhiming $\mathrm{Li}$, Yinglu $\mathrm{Li}$

Received: 14 December 2017 Revised: 6 April 2018 Accepted: 7 May 2018

Published online: 29 May 2018 
activation. ${ }^{20}$ Phosphorylation of TIP60 by c-Abl upon chromatin disruption promotes ATM acetylation and subsequent activation. ${ }^{21}$ Finally, DNA damage-induced displacement of the spliceosome and formation of R-loops activate ATM via a non-canonical pathway. ${ }^{22}$ Together, these reports suggest that ATM activation is indeed regulated by chromatin alterations.

The precise molecular mechanisms that are required to restrain ATM under basal conditions and trigger ATM activation upon DNA damage remain uncertain, but it is reasonable to speculate that ATM may be regulated by chromatin-related factors, such as the linker histone $\mathrm{H} 1$. Given that $\mathrm{H} 1$ is critical for modulating chromatin dynamics and genome stability, it is possible that $\mathrm{H} 1$, or one of its specific isoforms, may be associated with ATM activation. Here, we studied the role of linker histone $\mathrm{H} 1$ in the DNA damage response and repair. We report a novel mechanism by which $\mathrm{H} 1.2$, but not other $\mathrm{H} 1$ isoforms, regulates DNA damage response and repair through the repression of ATM recruitment and activation. Upon DNA damage, H1.2 is rapidly poly-ADP-ribosylated (PARylated) at its $C$ terminus and detaches from chromatin for degradation. Our data reveal a conceptually new functional link between chromatin alterations, H1.2 destabilization and ATM activation.

\section{RESULTS}

Linker histone $\mathrm{H} 1.2$ attenuates the ATM-dependent DNA damage response

To explore the potential connections between linker histone $\mathrm{H} 1$ and ATM, we generated $\mathrm{H} 1.2, \mathrm{H} 1.3$ and $\mathrm{H} 1.4$ variant-specific knockout (KO) HeLa cells using clustered regularly interspaced short palindromic repeats (CRISPR)-Cas9 technology (Fig. 1a). Notably, etoposide or ionizing radiation (IR)-induced phosphorylation of $\mathrm{H} 2 \mathrm{AX}, \mathrm{NBS} 1, \mathrm{SMC} 1$ and ATM was markedly elevated in $\mathrm{H} 1.2$ $\mathrm{KO}$ cells, but not in $\mathrm{H} 1.3$ or $\mathrm{H} 1.4 \mathrm{KO}$ cells (Fig. 1b, c; Supplementary information, Figure $\mathrm{S} 1 \mathrm{a}$ ). The formation of $\mathrm{\gamma}-\mathrm{H} 2 \mathrm{AX}$ foci upon DNA damage was also clearly promoted in $\mathrm{H} 1.2 \mathrm{KO}$ cells (Supplementary information, Figure S1b). Rescue experiments, we performed by transfecting $\mathrm{H} 1.2$ into $\mathrm{H} 1.2 \mathrm{KO}$ cells, showed that reintroduction of $\mathrm{H} 1.2$ could potently suppress the elevated ATM activation (Fig. 1c; Supplementary information, Figure S1c). Interestingly, PARylation, another chromatin modification in the initial response to DNA damage, was not altered when $\mathrm{H} 1.2$ was depleted (Supplementary information, Figure S1d). Moreover, the ultraviolet (UV)-induced DNA damage response was not influenced by H1.2 depletion (Supplementary information, Figure S1e), suggesting that H1.2 suppresses DNA double-strand break (DSB)-induced phosphorylation signaling.

To determine which kinase is involved in phosphorylation signaling opposed by $\mathrm{H} 1.2$, we pre-treated cells with specific inhibitors against ATM (Ku55933) or DNA-dependent protein kinase (DNA-PK) (Ku57788), as these two kinases have a known involvement in DSB-induced phosphorylation. ${ }^{23}$ Following DNA damage, H1.2 depletion-enhanced phosphorylation was abrogated in Ku55933-treated cells, but not Ku57788-treated cells (Supplementary information, Figure S1f). In addition, direct overexpression of $\mathrm{H} 1.2$ did not lead to significant inhibition of $\mathrm{y}-\mathrm{H} 2 \mathrm{AX}$ foci formation (Fig. 1d), indicating that $\mathrm{H} 1.2$ may only interfere with one of the redundant DSB-responding kinases. This accords with previous reports that inhibition of either ATM or DNA-PK alone showed limited effects on IR-induced $\gamma-\mathrm{H} 2 \mathrm{AX}{ }^{24}$ However, $\mathrm{H} 1.2$ over-expression led to markedly reduced $\mathrm{Y}-\mathrm{H} 2 \mathrm{AX}$ levels when DNA-PK was inhibited by Ku57788 treatment (Fig. 1d; Supplementary information, Figure $\mathrm{S} 1 \mathrm{~g}$ ), suggesting that $\mathrm{H} 1.2$ specifically inhibits ATM, but not DNA-PK activity. Similarly, the enhanced phosphorylation of ATM or its substrates resulting from $\mathrm{H} 1.2$ depletion was evidently prevented by ATM knockdown, but not by knockdown of ATR or DNA-PKcs (Fig. 1e; Supplementary information, Figure S1h and i). Moreover, H1.2 knockdown in ATMdeficient $A-T$ cells had no significant influence on $\mathrm{Y}-\mathrm{H} 2 \mathrm{AX}$ levels
(Fig. 1f), suggesting a direct role of ATM in H1.2-opposed phosphorylation signaling. Immunofluorescent staining after in situ detergent extraction also showed that $\mathrm{H} 1.2 \mathrm{KO}$ led to increased ATM activation and recruitment to chromatin upon DNA damage (Fig. 1g, h). Finally, although $\mathrm{H} 1.2$ depletion led to a mild cell cycle arrest in G1 phase, DNA damage-induced ATM activation was still increased upon $\mathrm{H} 1.2$ deletion when cells were synchronized using a double thymidine block (Supplementary information, Figure $\mathrm{S} 1 \mathrm{j}$ and $\mathrm{k}$ ), suggesting that regulation of ATM by $\mathrm{H} 1.2$ is independent of the cell cycle phase. These data indicate that $\mathrm{H} 1.2$ attenuates the ATM-dependent DNA damage response in vivo and protects chromatin from abnormal ATM recruitment and activation.

Linker histone H1.2 interacts with ATM and directly inhibits its activity

To test the possibility that $\mathrm{H} 1.2$ directly regulates ATM activity, we established an in vitro kinase assay whereby purified ATM protein was incubated with different ATM substrates, including an $\mathrm{N}$-terminal glutathione S-transferase (GST)-p53 (1-99 aa) peptide, free histones and mononucleosomes. ATM activity was markedly repressed when recombinant $\mathrm{H} 1.2$, but not $\mathrm{H} 1.4$, was introduced, as measured by the levels of p53 phosphorylation on serine 15 (S15) and $\mathrm{y}-\mathrm{H} 2 \mathrm{AX}$ (Fig. 2a; Supplementary information, Figure S2a and b). ATR kinase activity, however, was not affected by H1.2 (Supplementary information, Figure S2c). In addition, ATM exhibited lower activity towards mononucleosomes when H1.2 was over-expressed, as determined by the phosphorylation levels of ATM chromatin substrates (Fig. 2b; Supplementary information, Figure S2d). Together, these findings suggest that $\mathrm{H} 1.2$ directly inhibits ATM activity in vitro.

We next used a GST pull-down assay with purified fragments of GST-ATM and HIS-H1.2 to determine whether $\mathrm{H} 1.2$ directly interacts with ATM. We found that fragment 7 (F7) containing a specific region of ATM HEAT repeat domain (1239-1770 aa) directly interacted with H1.2 (Fig. 2c; Supplementary information, Figure S2e). GST-fragments of $\mathrm{H} 1.2$ were also purified and incubated with HIS-ATM F7 and the C-terminal domain of H1.2 (113-213 aa) was identified to be responsible for its binding to ATM (Fig. 2d; Supplementary information, Figure S2f). Accordingly, introduction of the H1.2 C-terminal domain attenuated ATM activity in vitro (Fig. 2e). In addition, mass spectrometric analysis of interacting proteins detected $\mathrm{H} 1.2$ as co-purifying with ATM, which was confirmed by subsequent co-immunoprecipitation (Co-IP) (Fig. 2f; Supplementary information, Figure S2g and h). Moreover, we showed that interaction between ATM and H1.2 was specific, as other $\mathrm{H} 1$ variants exhibited a much weaker binding affinity to ATM and the interacting domain was also different (Fig. 2g; Supplementary information, Figure S2i). Upon etoposideinduced DNA damage, the interaction between ATM and $\mathrm{H} 1.2$ was markedly decreased (Fig. 2h). The fact that the ATM HEAT repeat domain is critical for binding of its substrates prompted us to examine whether $\mathrm{H} 1.2$ interferes with ATM binding to other partners. Interestingly, we found that $\mathrm{H} 1.2$ reduced the binding of ATM to substrates that included $\mathrm{H} 2 \mathrm{AX}$ and p53 (Fig. 2i). Taken together, these findings confirm that $\mathrm{H} 1.2$ inhibits ATM activity via direct binding with the ATM HEAT repeat domain.

Linker histone H1.2 inhibits ATM recruitment and activation by interacting with MRN

MRN is known to be essential for the recruitment of ATM in DNA damage response. ${ }^{25}$ To clarify how H1.2 interferes with ATM recruitment, we therefore examined the relationship between $\mathrm{H} 1.2$ and the MRN complex. We found that H1.2 KO had little effect on the initial recruitment of the MRN complex, as monitored by live-cell imaging of GFP-NBS1 and GFP-MRE11 localization following laser micro-irradiation (Fig. 3a; Supplementary information, Figure S3a), suggesting that $\mathrm{H} 1.2$ may function downstream 
a

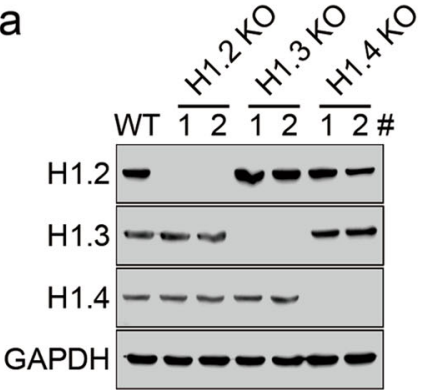

b

Etoposide (min) $\frac{\text { WT }}{03060} \frac{\mathrm{H} 1.2 \mathrm{KO}}{03060} \frac{\mathrm{H} 1.3 \mathrm{KO}}{03060} \frac{\mathrm{H} 1.4 \mathrm{KO}}{03060}$

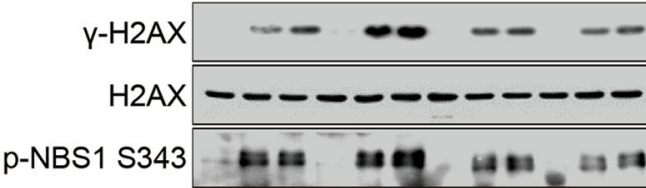

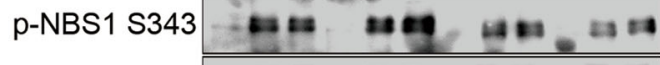

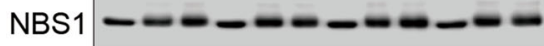

p-ATM S1981 $\cdots \cdots \quad-\infty \quad \cdots$
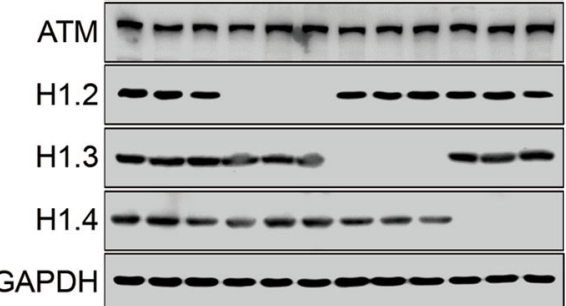

C

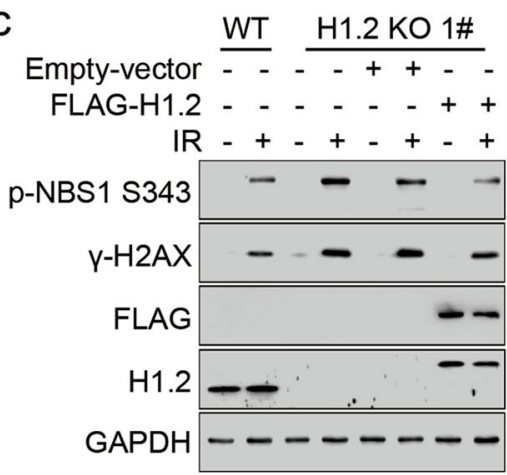

$f$

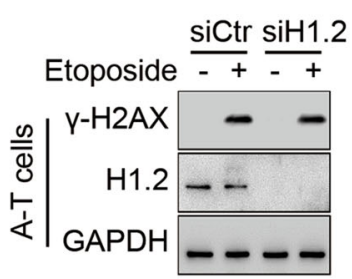

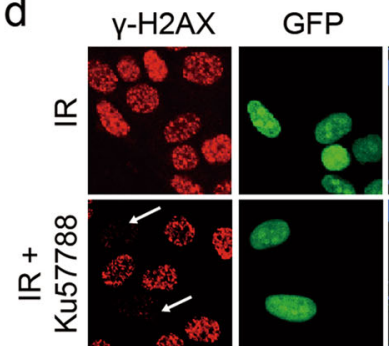
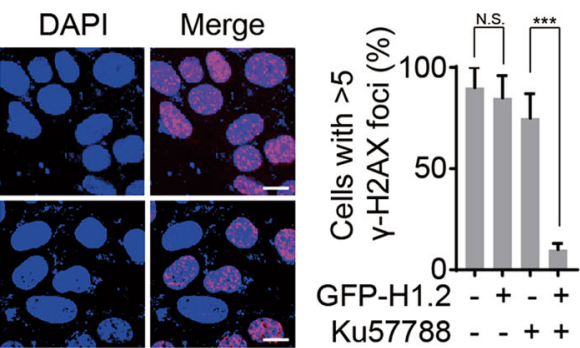

e

siCtr $\frac{\text { siCtr }}{++--\frac{\text { siATM 1\# }}{++--}} \frac{\text { siATM 2\# }}{++--}$

$\mathrm{siH} 1.2-t_{+}+-++-++$

Etoposide $-+-++{ }_{-}+-++$

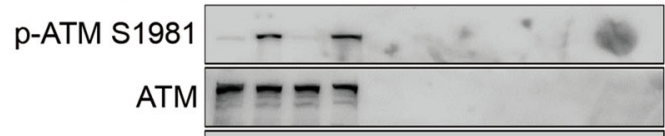

p-SMC1 S957 $-\infty-\ldots-\ldots-\cdots$

SMC1 $1---\cdots-\cdots-\cdots-$

p-NBS1 S343 + -

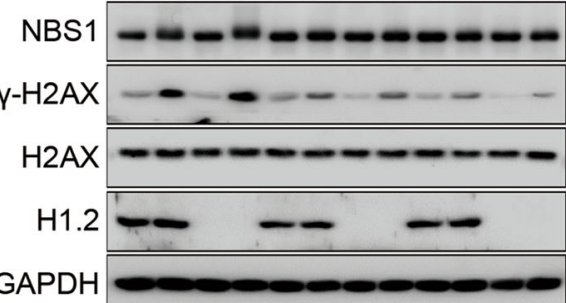

GAPDH
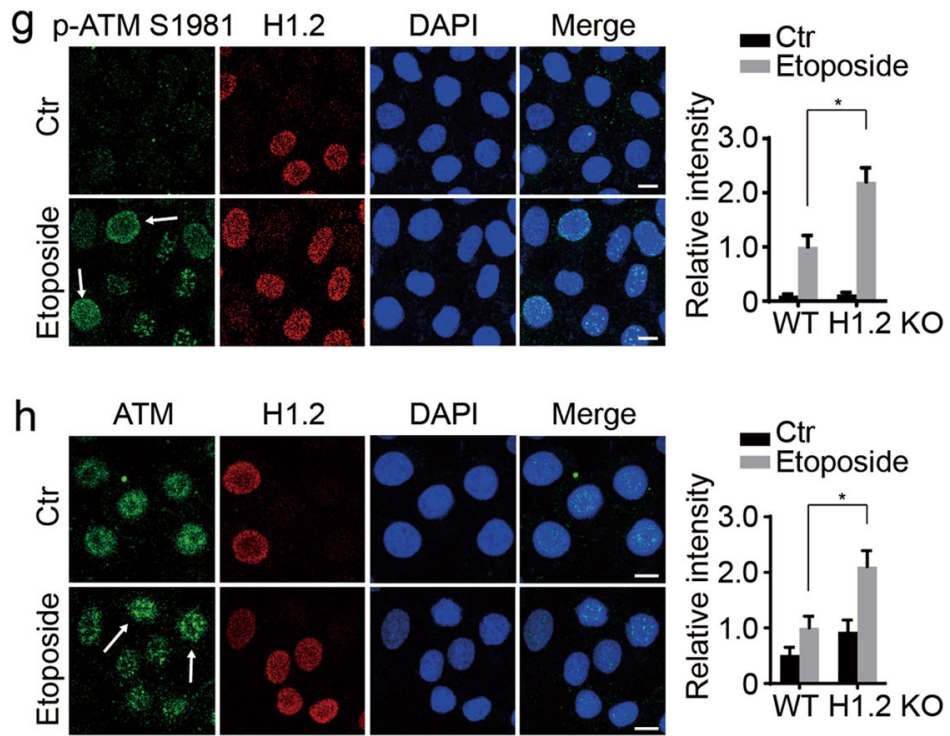

of MRN. We obtained similar results by chromatin fractionation and confocal microscopic analysis of MRN complex components after etoposide treatment (Supplementary information, Figure S3b and c). Further explorations of the interactions between the MRN complex and $\mathrm{H} 1.2$ by Co-IP showed that $\mathrm{H} 1.2$ interacted with the MRN complex (Fig. 3b; Supplementary information, Figure S3d). In addition, treatment with benzonase, a nuclease which cleaves multiple forms of DNA, did not alter the interaction (Fig. 3b), indicating that $\mathrm{H} 1.2$ interacts with MRN in a DNA-independent manner. Specifically, in vitro GST pull-down assays identified that the C-terminal domain of H1.2 directly interacted with MRE11, but not RAD50 or NBS1 (Fig. 3c, d; Supplementary information, Figure S3e). Similarly, the in vitro interaction was also not affected by benzonase (Supplementary information, Figure S3f), further suggesting that $\mathrm{H} 1.2$ directly interacts with MRE11. 
Fig. 1 Linker histone H1.2 attenuates the ATM-dependent DNA damage response. a Immunoblots for $\mathrm{H} 1.2, \mathrm{H} 1.3$ and $\mathrm{H} 1.4$ protein levels in wild-type, H1.2, H1.3 or H1.4 KO HeLa cells. 1\# and 2\# indicate two clones which were generated using different sgRNAs. b Wild-type, H1.2, $\mathrm{H} 1.3$ or H1.4 KO (1\#) HeLa cells were treated with $40 \mu \mathrm{M}$ etoposide for 0,30 and 60 min and analyzed by immunoblotting. c Wild-type and H1.2 KO (1\#) HeLa cells were transfected with the indicated plasmids with or without exposure to $10 \mathrm{~Gy}$ IR and analyzed by immunoblotting $1 \mathrm{~h}$ post IR. d HeLa cells were transfected with GFP-H1.2 and exposed to 10 Gy irradiation (IR) with or without $2 \mathrm{~h}$ prior exposure to $2 \mu \mathrm{M} \mathrm{Ku} 57788$. Cells were collected $1 \mathrm{~h}$ post IR and subjected to immunofluorescent assay. Cells with $>5 \gamma-\mathrm{H} 2 \mathrm{AX}$ foci were counted. The data represent the mean \pm SD. Scale bars, $10 \mu \mathrm{m}$. e HeLa cells were transfected with the indicated siRNAs and treated with $40 \mu \mathrm{M}$ etoposide for $2 \mathrm{~h}$ and analyzed by immunoblotting. f A-T cells were transfected with the indicated siRNAs and treated with $40 \mu \mathrm{M}$ etoposide for $1 \mathrm{~h}$ and analyzed by immunoblotting. g, h Wild type and H1.2 KO (1\#) HeLa cells were mixed and then treated with $40 \mu \mathrm{M}$ etoposide for $2 \mathrm{~h}$ or left untreated (Ctr) and analyzed by immunofluorescence. The intensity of ATM or phospho-ATM S1981 in the etoposide-treated wild-type cells was normalized to 1 . The arrows indicate representative cells. All data represent the mean \pm SD. Scale bars, $10 \mu \mathrm{m}$

To further determine whether $\mathrm{H} 1.2$ attenuates ATM recruitment and activation through MRN, we performed H1.2 knockdown in NBS1 KO or MRE11 knockdown cells. It was shown that deletion of NBS1 or MRE11 impaired ATM activation, whereas H1.2 depletion failed to rescue this repression (Fig. 3e, f), suggesting that both recruitment of MRN and release of $\mathrm{H} 1.2$ are required for ATM activation. In addition, the interaction between the MRN complex and ATM was attenuated by the over-expression of H1.2 even without DNA damage (Fig. 3g; Supplementary information, Figure S3g). Moreover, $\mathrm{C}$ terminally deleted $(\Delta \mathrm{C}) \mathrm{H} 1.2$, which could not interact with ATM or MRE11, failed to do so (Fig. 3h), indicating that $\mathrm{H} 1.2$ and MRN may compete for the binding of ATM. Upon etoposide treatment, the interaction between ATM and the MRN complex was enhanced, which could again be suppressed by over-expression of H1.2 (Fig. 3i; Supplementary information, Figure S3h). We could also show that over-expression of $\mathrm{H} 1.2$ did not alter the interaction between the MRN components (Fig. 3i; Supplementary information, Figure S3g and h). Together, these results suggest that H1.2 inhibits ATM recruitment and subsequent activation by sequestering its binding to the MRN complex.

Linker histone $\mathrm{H} 1.2$ is rapidly displaced and degraded upon DNA damage

To better understand how $\mathrm{H} 1.2$ regulates ATM activity under physiological conditions, we examined the dynamics of linker histone in response to DNA damage. Interestingly, after exposing cells to etoposide or IR and analyzing the chromatin fractions, we found that linker histone $\mathrm{H} 1.2$, but not other $\mathrm{H} 1$ isoforms, was displaced from chromatin, correlating with recruitment and activation of ATM (Fig. 4a, b; Supplementary information, Figure S4a). At later stages of DNA damage repair, $\mathrm{H} 1.2$ was gradually restored when chromatin ATM was restored to its basal level (Fig. 4a), which may be associated with completion of the repair process. A chromatin immunoprecipitation (ChIP) assay in DR-GFP U2OS cells also showed that $\mathrm{H} 1.2$ dissociated from chromatin upon I-Scel-induced DNA damage whereas H1.4 levels showed no detectable changes at the I-Scel damage site (Fig. 4c). Further experiments using laser micro-irradiation coupled live-cell imaging of GFP-H1.2 localization demonstrated that the dissociation of $\mathrm{H} 1.2$ took place immediately $(<10 \mathrm{~s})$ after DNA damage was elicited (Fig. 4d). Staining to reveal endogenous H1.2 after laser micro-irradiation also confirmed that $\mathrm{H} 1.2$ was rapidly displaced in the irradiation path (Supplementary information, Figure S4b).

To investigate whether H1.2 is destabilized after DNA damage, we treated cells with different DNA damaging stimuli and then assessed $\mathrm{H} 1.2$ expression. $\mathrm{H} 1.2$ protein levels specifically decreased in response to various DNA damage treatments in different cell lines, whereas the levels of $\mathrm{H} 1.3$ and $\mathrm{H} 1.4$ were unaltered (Fig. 4e; Supplementary information, Figure S4c). The mRNA levels of $\mathrm{H} 1.2$ were not obviously decreased, indicating that the decrease of $\mathrm{H} 1.2$ was likely due to protein degradation (Supplementary information, Figure S4d). In addition, DNA damage-induced degradation of $\mathrm{H} 1.2$ was both time-dependent and dose-dependent (Supplementary information, Figure S4e).
Moreover, H1.2 degradation was not induced by UV, which mainly causes single strand breaks (SSBs) (Supplementary information, Figure S4f). Furthermore, we treated cells with a proteasome inhibitor (MG132) or a lysosome inhibitor (chloroquine, CHQ) to determine which pathway might be responsible for $\mathrm{H} 1.2$ degradation. As shown in Fig. 4f, MG132 markedly blocked H1.2 degradation, suggesting that $\mathrm{H} 1.2$ was degraded in a proteasomedependent pathway. An in vitro degradation assay consistently showed that $\mathrm{H} 1.2$, but not $\mathrm{H} 1.4$, was degraded by $20 \mathrm{~S}$ proteasomes (Supplementary information, Figure S4g). The degradation was further confirmed to be a ubiquitin-independent process in the cytoplasm (Supplementary information, Figure S4h and i). Interestingly, H1.2 degradation was markedly blocked when treated with a specific $20 \mathrm{~S}$ proteasome inhibitor (Oprozomib), whereas ATM activation was also evidently inhibited (Fig. 4g), suggesting a positive feedback loop between H1.2 destabilization and ATM activation.

To further confirm the connection between $\mathrm{H} 1.2$ destabilization and ATM activation, we next treated cells with either $\mathrm{NaCl}$ or HDAC inhibitors (trichostatin A [TSA] and sodium butyrate $[\mathrm{NaB}]$ ), which are known to activate ATM without causing DNA damage. ${ }^{13}$ Surprisingly, TSA and NaB could induce H1.2 degradation in a time-dependent and dose-dependent manner, respectively (Fig. 4h). H1.2 was also degraded following sodium chloride treatment, and this was accompanied by activation of ATM (Fig. 4i). Together, these results suggest a correlation between chromatin alterations, H1.2 destabilization and ATM activation.

\section{H1.2 PARylation permits its chromatin displacement upon DNA} damage

Previous data supports the notion that $\mathrm{H} 1$ dynamics are tightly regulated by its post-translational modifications (PTMs). ${ }^{26} \mathrm{We}$ therefore decided to address the mechanisms of DNA damageinduced H1.2 dynamics. Both live-cell imaging and staining of endogenous H1.2 indicated that a specific PARP inhibitor (PJ34), but not ATM or DNA-PKCs inhibitors, significantly repressed the dissociation of $\mathrm{H} 1.2$ from chromatin upon laser micro-irradiation (Fig. 5a; Supplementary information, Figure S5a). Mutation of known or putative $\mathrm{H} 1.2$ phosphorylation sites that may affect $\mathrm{H} 1$ 's chromatin binding affinity resulted in only minimal effects on $\mathrm{H} 1.2$ displacement (Supplementary information, Figure S5b). Similarly, DNA damage-induced $\mathrm{H} 1.2$ dissociation was evidently delayed in PARP1 knockdown HeLa cells and Parp1 KO (Parp1 ${ }^{-/-}$) mouse embryonic fibroblasts (MEFs), as confirmed by chromatin fractionation (Fig. 5b, c). As expected, PJ34 inhibited the DNA damageinduced degradation of H1.2 (Supplementary information, Figure S5c).

We then examined how the DNA damage-induced $\mathrm{H} 1.2$ dynamics are regulated by PARP1, which is known to catalyze histone PARylation in the DNA damage response. ${ }^{27}$ We detected PARylation of H1.2 upon DNA damage, which was suppressed in the presence of PJ34 (Fig. 5d). In addition, HIS-H1.2 was PARylated when incubated with recombinant human PARP1, activated DNA and $\mathrm{NAD}^{+}$, and this effect was repressed when PJ34 was added to the in vitro reaction (Fig. 5e; Supplementary information, 
a

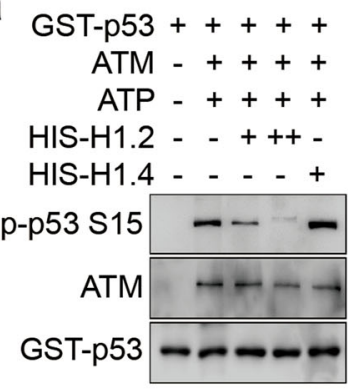

GST-p53 +++++

$-++t$

IS-H1.2 - - +++ -

HIS-H1.4 - - - +

b

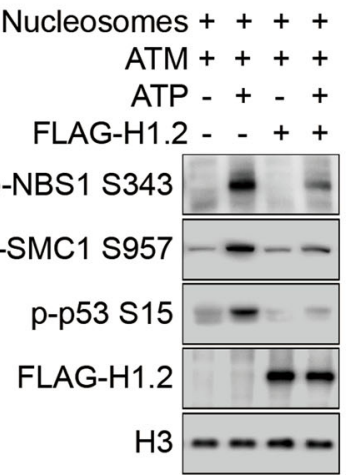

C

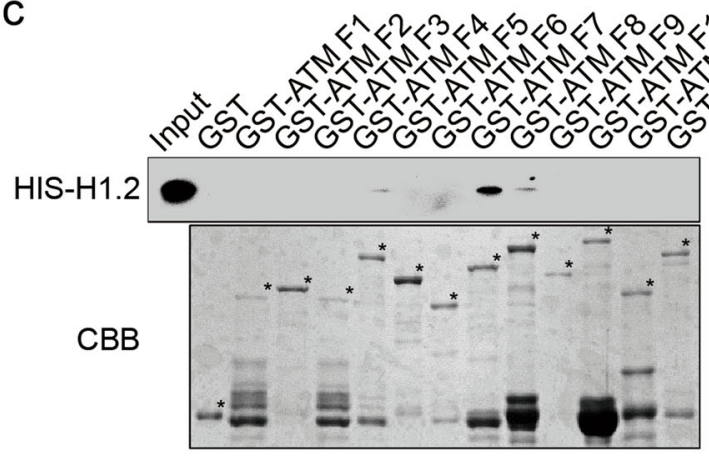

e

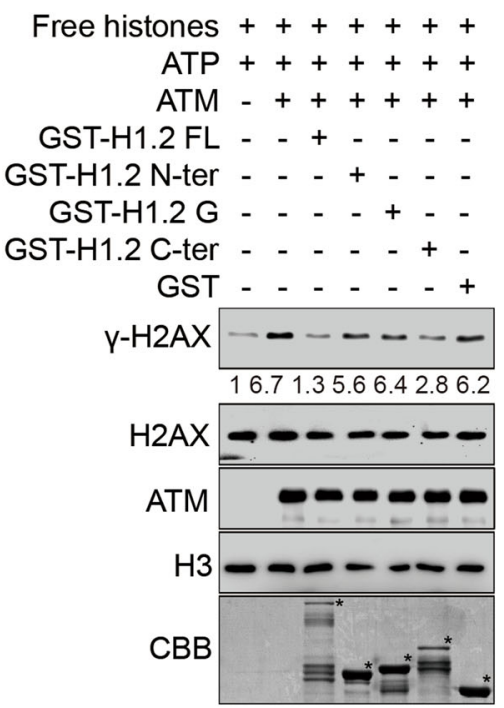

f

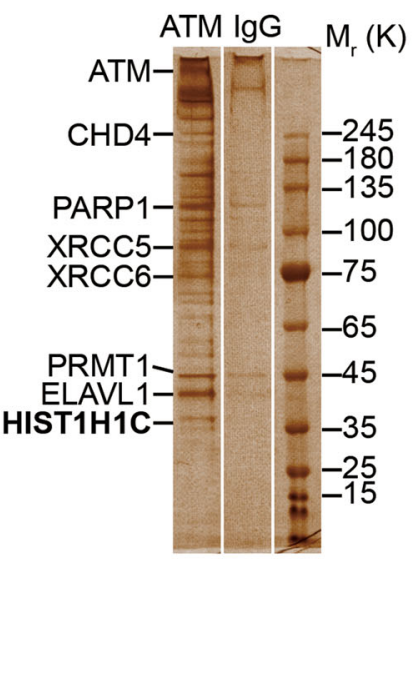

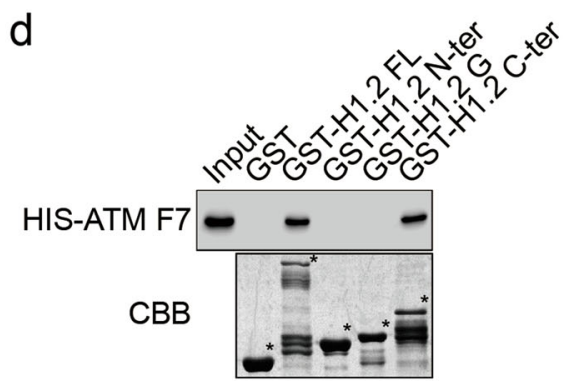

g

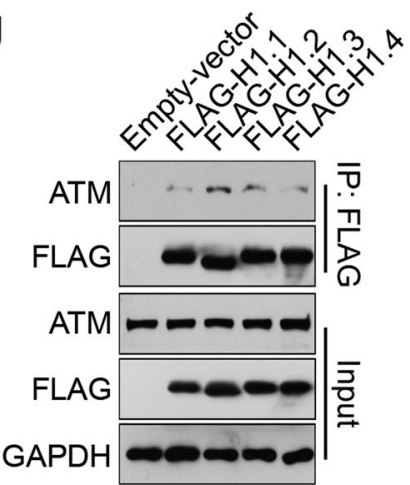

h Empty-vector + - -

FLAG-H1.2 - + +

Etoposide - - +

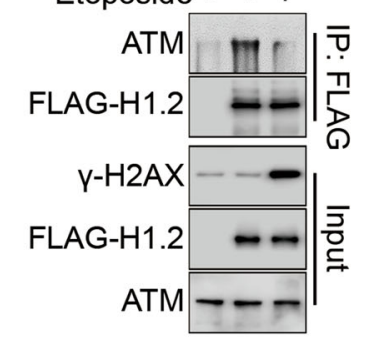

i

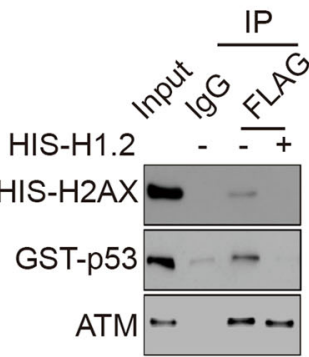

Fig. 2 Linker histone H1.2 interacts with ATM and directly inhibits its activity. a An N-terminal GST-p53 (1-99 aa) peptide was used as a substrate for in vitro phosphorylation assay with or without HIS-H1.2/H1.4. b HCT116 cells were transfected with FLAG-H1.2 or an empty vector and mononucleosomes were extracted and subjected to in vitro phosphorylation. c GST alone or GST-ATM fragments were incubated with HIS-H1.2 for the GST pull-down assay. * indicates specific protein bands. d GST alone or GST-H1.2 fragments were incubated with HISATM fragment 7 (F7, 1239-1770 aa) for GST pull-down assay. * indicates specific protein bands. e Free histones extracted from HeLa cells were used as substrates for in vitro phosphorylation in the presence of GST-H1.2 fragments or GST alone. The relative intensity of $\gamma-\mathrm{H} 2 \mathrm{AX} / \mathrm{H} 2 \mathrm{AX}$ was calculated. * indicates specific protein bands. f Total HeLa cell lysates were immunoprecipitated with anti-ATM or anti-lgG antibodies. The precipitated proteins were analyzed by mass spectrometry after SDS-PAGE electrophoresis and silver staining. Name in bold indicates the desired protein. $\mathbf{g}$ HEK293T cells were transfected with the indicated plasmids and subjected to Co-IP assay with FLAG-conjugated M2 beads. h HeLa cells were transfected with FLAG-H1.2 or an empty vector and treated as indicated with $40 \mu \mathrm{M}$ etoposide for $2 \mathrm{~h}$. Total cell lysates were immunoprecipitated using FLAG-conjugated M2 beads and analyzed by immunoblotting. i ATM was immunoprecipitated using FLAGconjugated M2 beads in HEK293T cells overexpressed with FLAG-ATM and incubated with $(-)$ or without $(+)$ recombinant HIS-H1.2 in kinase buffer. Recombinant ATM substrates, including HIS-H2AX (full-length) and GST-p53 (amino acids 1-99) were incubated without ATP. The interacting proteins were eluted and analyzed by immunoblotting 
a
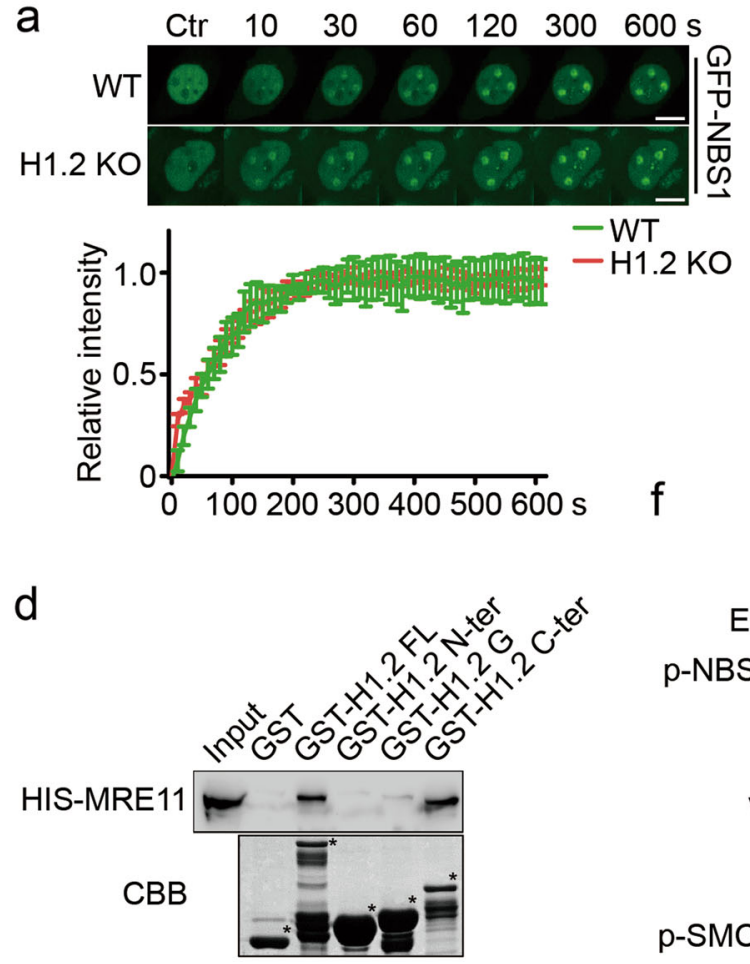

e

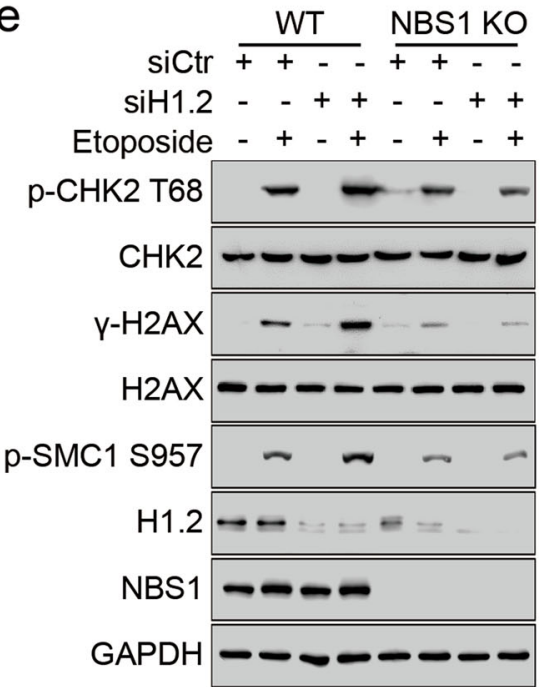

b

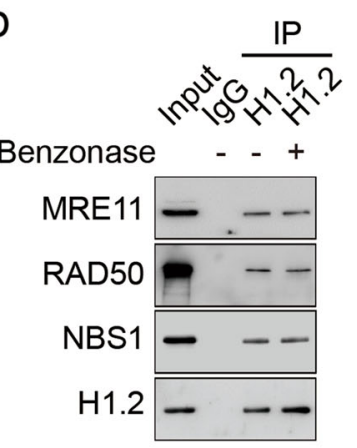

C

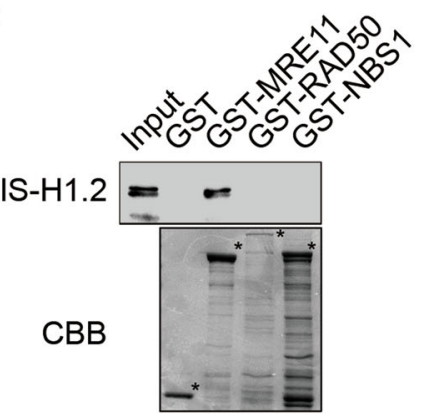

h Empty-vector + - GFP-H1.2 WT - + GFP-H1.2 $\Delta \mathrm{C}-\cdots+$

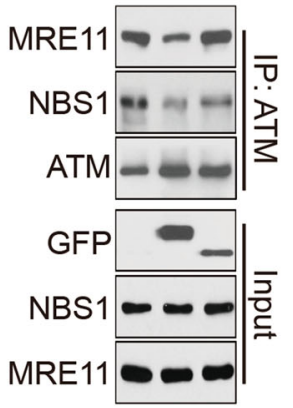

g

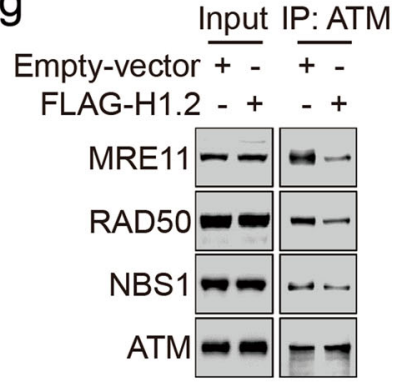

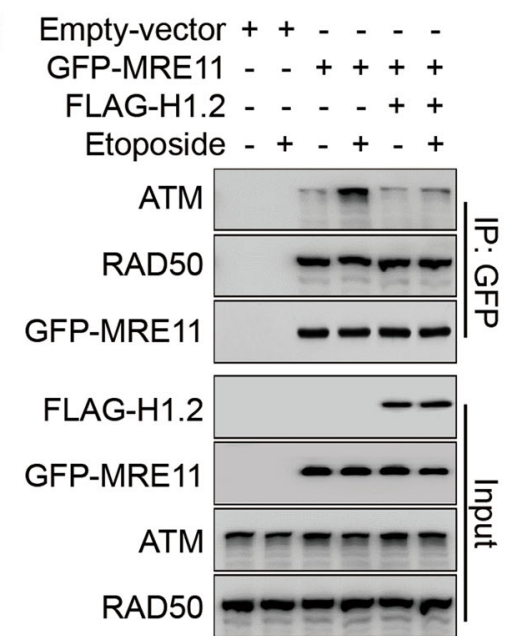

Fig. 3 Linker histone H1.2 inhibits ATM recruitment and activation by interacting with MRN. a Wild type and H1.2 KO (1\#) HeLa cells were transfected with GFP-NBS1 and subjected to laser micro-irradiation-coupled live-cell imaging. Images were taken every $10 \mathrm{~s}$ for 10 min and the relative intensity of the irradiation path signal was shown. The data represent the mean \pm SD. Scale bars, $10 \mu \mathrm{m}$. $\mathbf{b}$ HeLa cells extracts were analyzed by Co-IP assay with or without benzonase treatment with the indicated antibodies. c GST alone or GST-MRE11, RAD50 and NBS1 were incubated with HIS-H1.2 for GST pull-down assay. * indicates specific protein bands. d GST alone or GST-H1.2 fragments were incubated with HIS-MRE11 for GST pull-down assay. * indicates specific protein bands. e Wild type or NBS1 KO HeLa cells were transfected with the indicated siRNAs and treated with $40 \mu \mathrm{M}$ etoposide for $2 \mathrm{~h}$ and analyzed by immunoblotting. $\mathrm{f}$ HeLa cells were transfected with the indicated siRNAs and treated with $40 \mu \mathrm{M}$ etoposide for $2 \mathrm{~h}$ and analyzed by immunoblotting. $\mathbf{g}$, $\mathbf{h}$ HeLa cells were transfected with the indicated plasmids, and the whole cell lysates were immunoprecipitated with ATM antibody and analyzed by immunoblotting. i HeLa cells were transfected with the indicated plasmids and treated with $40 \mu \mathrm{M}$ etoposide for $2 \mathrm{~h}$. Whole cell extracts were prepared and analyzed by Co-IP assay and immunoblotting with the indicated antibodies 
a
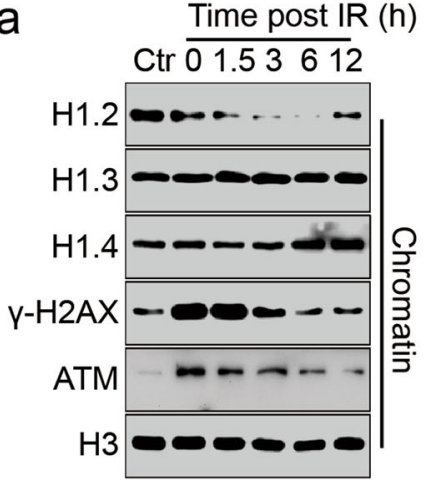

b

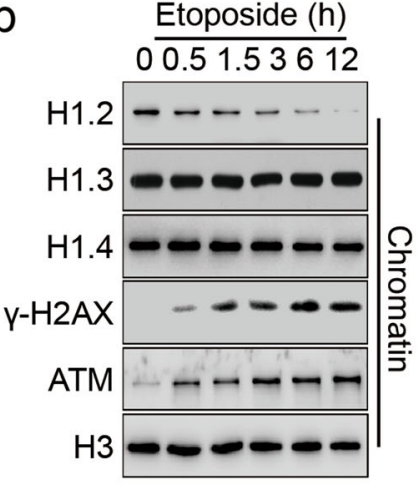

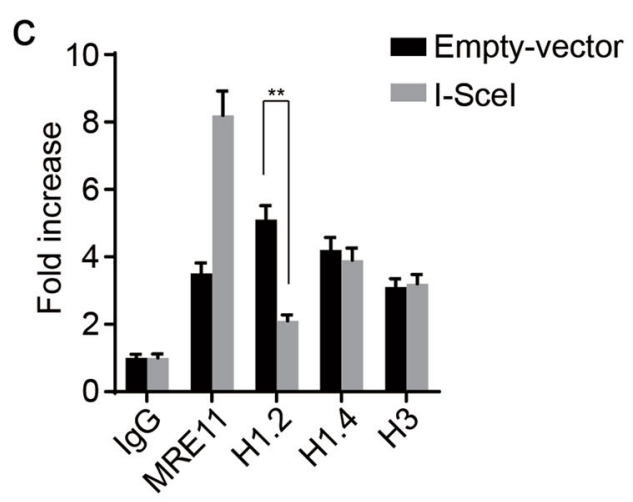

d

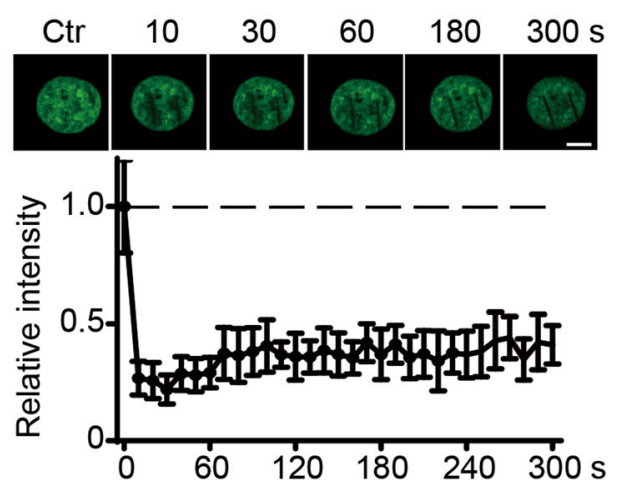

e

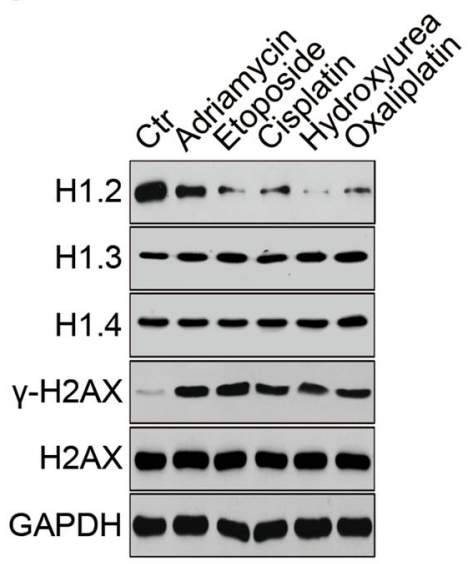

f

Etoposide - + - + - + MG132 - - + + - $\mathrm{CHQ}$ - - - - + +

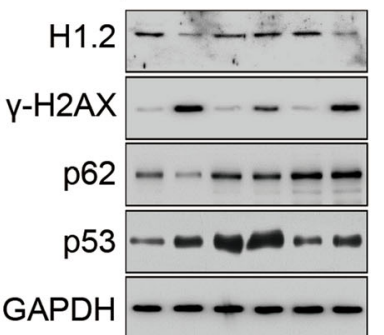

g Etoposide -+++
Oprozomib - - + ++

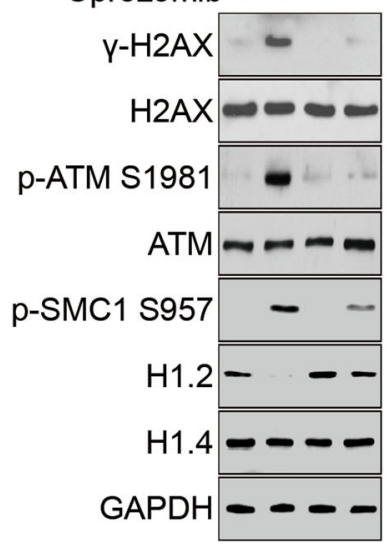

h

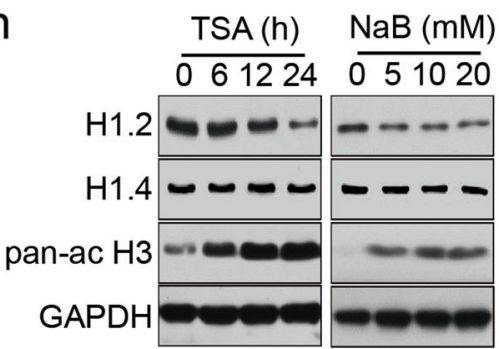

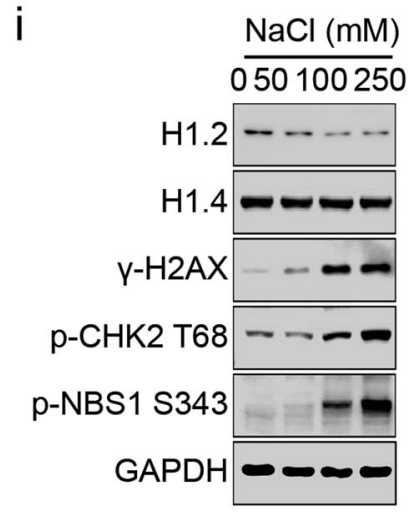

Fig. 4 Linker histone H1.2 is rapidly displaced from chromatin and degraded upon DNA damage. a, b HeLa cells were exposed to 10 Gy irradiation (IR) and released at the indicated time or treated with $20 \mu \mathrm{M}$ etoposide for the indicated time. Chromatin was fractionated and subjected to immunoblotting. c DR-GFP U2OS cells were transfected with I-Scel endonuclease or an empty vector and subjected to chromatin immunoprecipitation with the indicated antibodies followed by real-time PCR $48 \mathrm{~h}$ post transfection. All data represent the mean \pm SD. $\mathbf{d}$ HeLa cells were transfected with GFP-H1.2 and subjected to laser micro-irradiation-coupled live-cell imaging. The initial signal intensity of GFP-H1.2 was normalized to 1 and $\sim 15$ IR paths from 10 separate cells were calculated. All data represent the mean \pm SD. Scale bars, $10 \mu \mathrm{m}$. e HeLa cells were treated with either $1 \mu \mathrm{M}$ adriamycin at $1 \mu \mathrm{M}, 20 \mu \mathrm{M}$ etoposide, $10 \mu \mathrm{M}$ cisplatin, $2 \mathrm{mM}$ hydroxyurea or $10 \mu \mathrm{M}$ oxaliplatin for $12 \mathrm{~h}$ and analyzed by immunoblotting. f HeLa cells were treated with $1 \mu \mathrm{M}$ MG132 or $50 \mu \mathrm{M}$ CHQ for $12 \mathrm{~h}$ with or without $20 \mu \mathrm{M}$ etoposide and analyzed by immunoblotting. $\mathrm{g}$ HeLa cells were treated with etoposide at $20 \mu \mathrm{M}$ for $12 \mathrm{~h}$ with or without Oprozomib at $100 \mathrm{nM}$ and analyzed by immunoblotting. $\mathbf{h}$ HeLa cells were treated with $1 \mu \mathrm{M}$ TSA for the indicated time or to increasing concentrations of sodium butyrate (NaB) for $12 \mathrm{~h}$ and analyzed by immunoblotting. A pan-ac $\mathrm{H} 3$ antibodies was used as a positive control. $\mathbf{i}$ HeLa cells were exposed to increasing concentrations of sodium chloride $(\mathrm{NaCl})$ for $2 \mathrm{~h}$ and analyzed by immunoblotting

Figure S5d). Moreover, we analyzed H1.2 fragments to map the possible PARylation site(s) and found that deletion of the H1.2 Cterminal domain $(\Delta C)$ or a short extreme $C$ terminus $(\Delta C 1)$ largely abrogated PARP1-mediated PARylation (Supplementary information, Figure $\mathrm{S} 5 \mathrm{e}$ and $\mathrm{f}$ ). Previous reports and bioinformatic analyses $^{28}$ together predict that serine 188 of $\mathrm{H} 1.2$ is a major
PARylation site. Our in vivo and in vitro experiments demonstrated that mutation of this site (S188A) markedly diminished DNA damage-induced and PARP1-mediated PARylation of H1.2 (Fig. 5f, g). Live-cell imaging of the signal intensity across a laser microirradiation path also illustrated that the S188A mutation delayed DNA damage-induced H1.2 displacement from chromatin (Fig. 5h). 
a
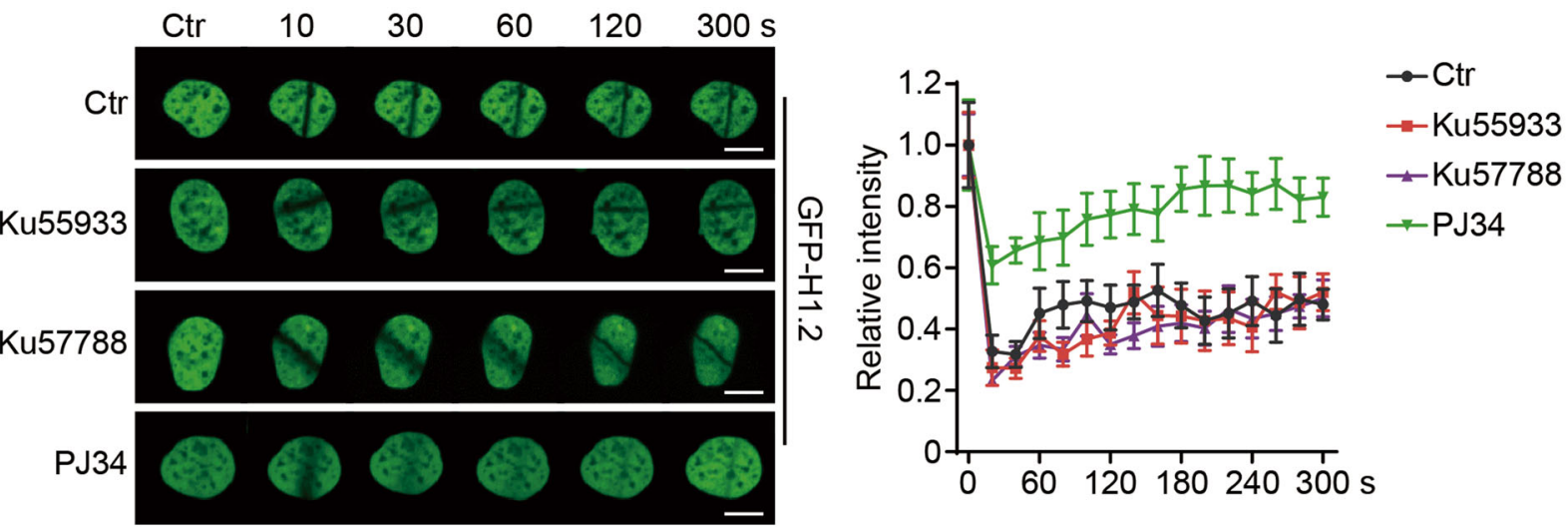

b

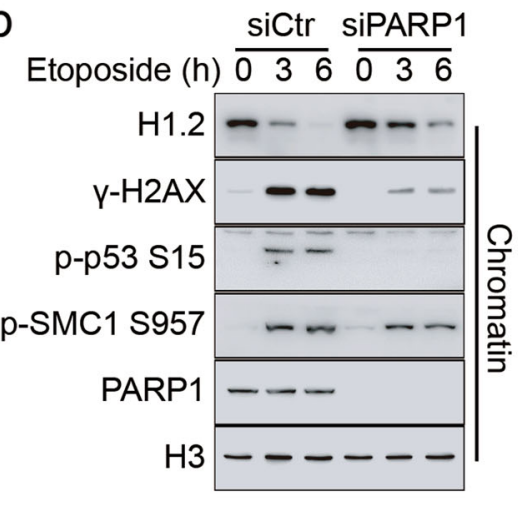

C

Parp1+/+ Parp1-1-

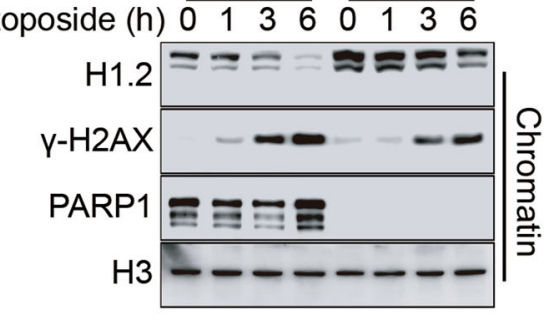

h

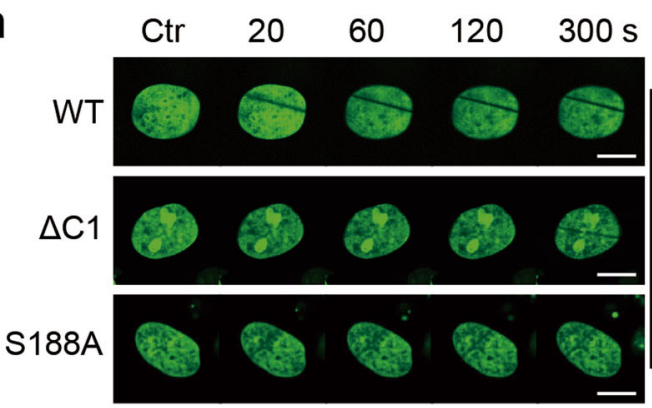

d

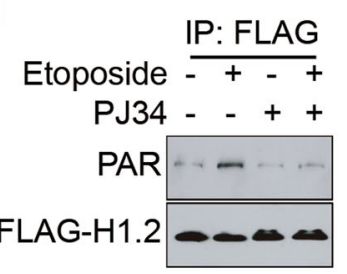

e

PARP $1++++$ HIS-H1. $2++++$

NAD + - + - +

PJ34 - - + +

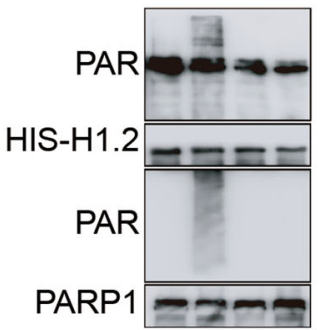

f

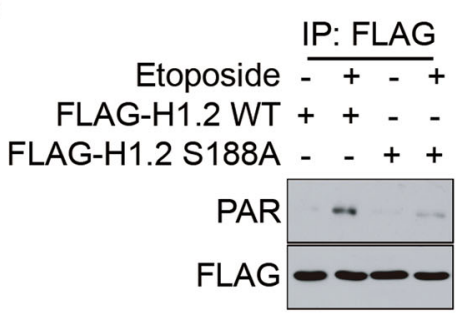

g

PARP $1++++$

NAD +-++

HIS-H1.2 WT - + - -

HIS-H1.2 S188A - - + -

HIS-H1.2 $\Delta \mathrm{C} 1$ - - - +

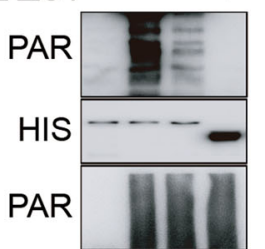

Fig. 5 H1.2 PARylation permits its displacement from chromatin upon DNA damage. a HeLa cells were transfected with GFP-H1.2 and treated with $20 \mu \mathrm{M}$ Ku55933 or $2 \mu \mathrm{M}$ Ku57788 for $4 \mathrm{~h}$ or $5 \mu \mathrm{M}$ PJ34 for $1 \mathrm{~h}$ followed by laser micro-irradiation. Images were taken every $10 \mathrm{~s}$ for 5 min and quantifications of the IR path signal intensity were shown and 15 IR paths from 10 separate cells were calculated. The data represent the mean \pm SD. Scale bars, $10 \mu \mathrm{m}$. b HeLa cells were transfected with the indicated siRNAs and treated with $40 \mu \mathrm{M}$ etoposide for the indicated time. Chromatin was fractionated and analyzed by immunoblotting. c Parp1 wild-type $(+/+)$ or KO $(-/-)$ MEFs were treated with $40 \mu \mathrm{M}$ etoposide for the indicated time and chromatin was fractionated and analyzed by immunoblotting. $\mathbf{d}$ HeLa cells were transfected with FLAG$\mathrm{H} 1.2$ and treated with $40 \mu \mathrm{M}$ etoposide for 15 min with or without $5 \mu \mathrm{M}$ PJ34 for $1 \mathrm{~h}$. Cell extracts were immunoprecipitated with FLAGconjugated M2 beads. e Recombinant HIS-H1.2 was subjected to in vitro PARylation assay in the presence of NAD ${ }^{+}$or $10 \mu \mathrm{M}$ PJ34, as indicated. f HeLa cells were transfected with wild-type or S188A mutated FLAG-H1.2 and treated with $40 \mu \mathrm{M}$ etoposide for 15 min with or without $5 \mu \mathrm{M}$ PJ34 for $1 \mathrm{~h}$, as indicated. Cells were extracted and immunoprecipitated with FLAG-conjugated M2 beads. g Recombinant wild-type, S188A mutated or $\mathrm{C} 1$-deleted $(\Delta \mathrm{C} 1)$ HIS-H1.2 were subjected to in vitro PARylation assay. $\mathbf{h}$ HeLa cells were transfected with wild-type, $\Delta \mathrm{C} 1$ or S188A mutated GFP-H1.2 and subjected to laser micro-irradiation. Images were taken every $20 \mathrm{~s}$ for 5 min and representative images were shown. Quantifications were calculated as in a. The data represent the mean \pm SD. Scale bars, $10 \mu \mathrm{m}$ 
a

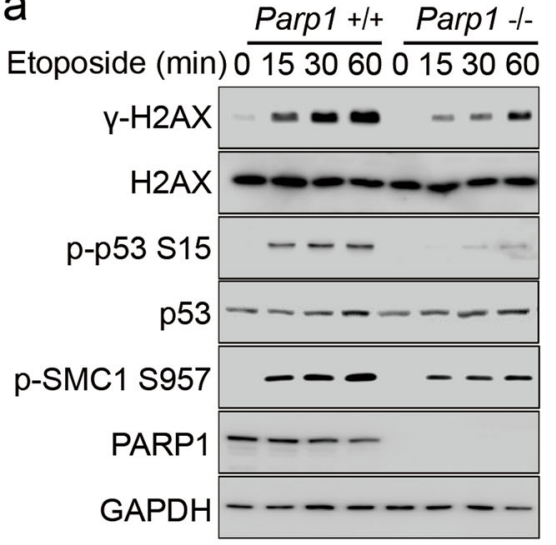

Etoposide (min) $\frac{\mathrm{Ctr}}{0153060} \frac{\mathrm{PJ} 34}{0153060}$

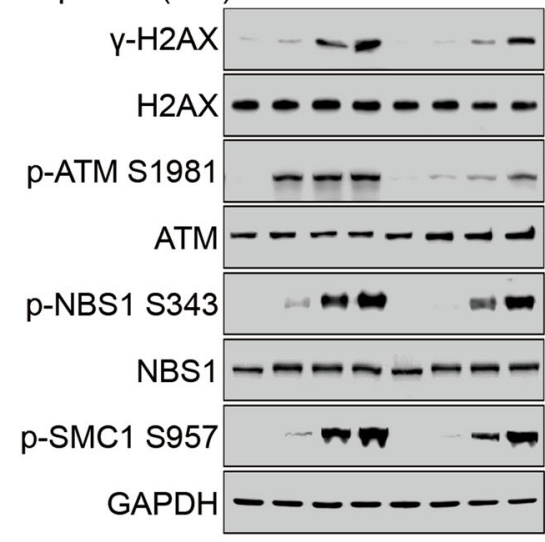

C

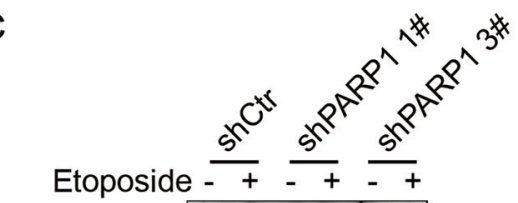

d

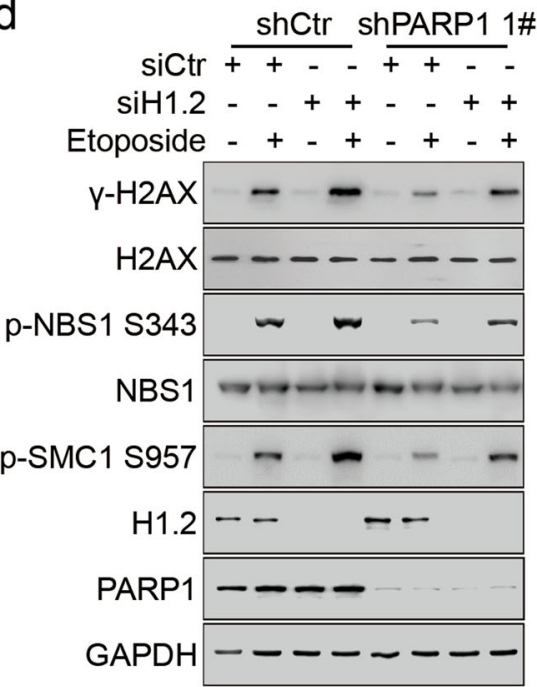

e

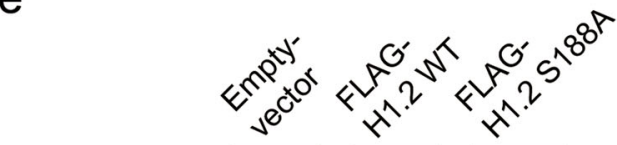

Etoposide (min) $\overline{03060} \overline{03060} \overline{03060}$

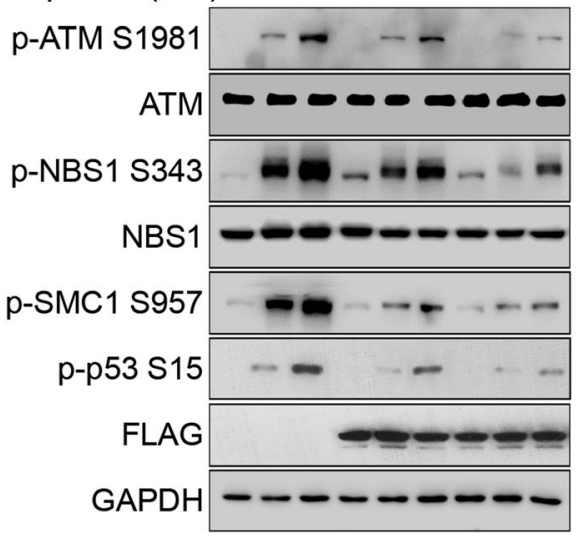

g $P A$

PARP1 - - - + +

HIS-H1.2 - - + + + -

GST-p53 + + + + +

ATM -+++ ด

ATP - +++ N

p-p53 S15

ATM

GST-p53

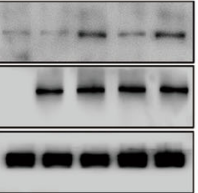

h

PARP1 +++

GST + - -

GST-H1.2 芩 - + +

NAD+ 을 - - +

HIS-MRE11

CBB

i Empty-vector + - - -

FLAG-H1.2 - + + +

Etoposide - - + +

PJ34 - - - +

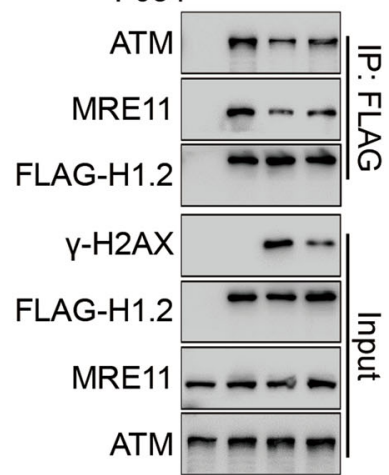

f

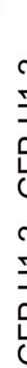

p-ATM S1981

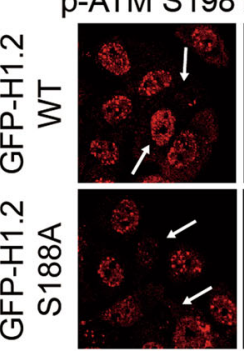

GFP

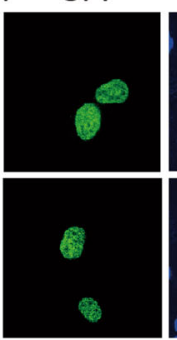

DAPI

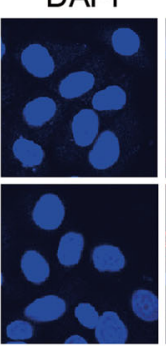

Merge

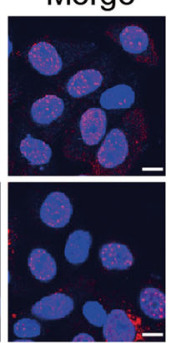

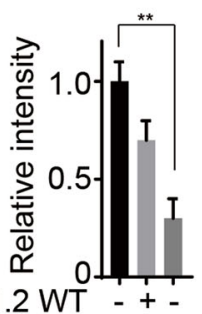

H1.2 WT - + -
Notably, the $\triangle \mathrm{C} 1$ mutant displayed an even more significant delay in H1.2 displacement than S188A (Fig. 5h), suggesting that additional sites may be involved in regulating $\mathrm{H} 1.2$ dynamics. Furthermore, cycloheximide (CHX) chase experiments showed that the H1.2 S188A mutant was more stable than wild-type H1.2 and etoposide-induced $\mathrm{H} 1.2$ degradation was also markedly blocked when S188 was mutated (Supplementary information, Figure $\mathrm{S} 5 \mathrm{~g}$ and $\mathrm{h}$ ). Together, these results indicate that H1.2 is dynamically regulated via PARP1-mediated PARylation of its C terminus.
PARylation of linker histone H1.2 is essential for DNA damageinduced ATM activation

ATM activation in $\mathrm{Parp}^{-/-}$MEFs was attenuated following etoposide treatment, consistent with an inhibitory role for $\mathrm{H} 1.2$ in regulating ATM (Fig. 6a). Accordingly, inhibition (with PJ34) or knockdown of PARP1 (by stably expressed shRNA) led to compromised ATM activation (Fig. 6b, c; Supplementary information, Figure S5i). This inhibition of ATM activation by PARP1 knockdown or inhibition was restored by H1.2 knockdown (Fig. 6d; Supplementary information, Figure S5j). In addition, over- 
Fig. 6 PARylation of $\mathrm{H} 1.2$ is essential for ATM activation. a Parp1 wild-type (+/+) or KO (-/-) MEFs were treated with $40 \mu \mathrm{M}$ etoposide for the indicated time and analyzed by immunoblotting. b HeLa cells were treated with $40 \mu \mathrm{M}$ etoposide for the indicated time with or without exposure to $5 \mu \mathrm{M}$ PJ34 $1 \mathrm{~h}$ before etoposide treatment and analyzed by immunoblotting. c Two clones of PARP1 stable knockdown (shPARP1 $\# 1$ and \#3) and control (shCtr) HeLa cells were treated with $40 \mu \mathrm{M}$ etoposide for $30 \mathrm{~min}$ and analyzed by immunoblotting. $\mathbf{d}$ shPARP1 (1\#) and shCtr HeLa cells were transfected with the indicated siRNAs and treated with $40 \mu \mathrm{M}$ etoposide for 30 min and analyzed by immunoblotting. e HCT116 cells were transfected with the indicated plasmids and treated with $40 \mu \mathrm{M}$ etoposide for the indicated times and analyzed by immunoblotting. f HeLa cells were transfected with wild-type or S188A mutated GFP-H1.2, treated with $40 \mu \mathrm{M}$ etoposide for $2 \mathrm{~h}$ and the fluorescence intensity of phospho-ATM S1981 in the untransfected cells was normalized to 1 . The arrows indicate representative cells. The data represent the mean \pm SD. Scale bars, $10 \mu \mathrm{m}$. g Recombinant HIS-H1.2 was incubated for 30 min at $37^{\circ} \mathrm{C}$ with PARP1 with or without NAD ${ }^{+}$ for in vitro PARylation assay (Incubation 1, Inc. 1). H1.2 was eluted and used for in vitro phosphorylation assay (Incubation 2, Inc. 2). An Nterminal GST-p53 (1-99 aa) peptide was used as the substrate. $\mathbf{h}$ Recombinant GST-H1.2 was incubated with PARP1 with or without NAD ${ }^{+}$for in vitro PARylation assay. GST alone and PARylated GST-H1.2 were then incubated with HIS-MRE11 for GST-pulldown assay. ${ }^{*}$ indicates specific protein bands. i HeLa cells were transfected with the indicated plasmids and treated with $40 \mu \mathrm{M}$ etoposide for $1 \mathrm{~h}$ or $5 \mu \mathrm{M} \mathrm{PJ34}$ for $1 \mathrm{~h}$. Whole cell extractions were prepared and subjected to Co-IP assay with FLAG-conjugated M2 beads

expression of H1.2 S188A repressed ATM activation (Fig. 6e). Consistently, positive immunofluorescent staining of p-ATM S1981 was not detected in the majority of cells over-expressing $\mathrm{H} 1.2$ S188A (Fig. 6f), further supporting the notion that PARP1 regulates ATM activation through PARylation and displacement of H1.2.

To investigate the direct role of $\mathrm{H} 1.2$ PARylation in regulating ATM activity, we established a two-step in vitro experiment: recombinant $\mathrm{H} 1.2$ was first PARylated in vitro (Incubation 1, Inc. 1). The PARylated $\mathrm{H} 1.2$ was then added to an in vitro ATM phosphorylation system in which an N-terminal GST-p53 (1-99 aa) peptide was used as a substrate (Incubation 2, Inc. 2). By measuring the levels of p53 S15 phosphorylation, we found that unmodified $\mathrm{H} 1.2$ potently inhibited ATM activity, whereas PARylated H1.2 exhibited weaker effects in repressing ATM activation (Fig. 6g). Similarly, PARylated H1.2 showed decreased binding to MRE11, as demonstrated by an in vitro pull-down assay using differentially PARylated H1.2 (Fig. 6h). In addition, inhibition of PARP1 by PJ34 restored DNA damage-induced reduction of the interaction between $\mathrm{H} 1.2$ and ATM or MRE11 (Fig. 6i). Together, these data suggest that PARylation of $\mathrm{H} 1.2$ is required for ATM activation in response to DNA damage.

Linker histone $\mathrm{H} 1.2$ dissociation and destabilization are required for DNA repair and cell survival

To clarify the biological functions of $\mathrm{H} 1.2$ and its modifications, we investigated its role in DNA damage repair and cell survival. Global chromatin structure and cell survival were unaltered in $\mathrm{H} 1.2 \mathrm{KO}$ cells without DNA damage, as measured by micrococcal nuclease sensitivity and colony formation assays (Supplementary information, Figure $\mathrm{S} 6 \mathrm{a}$ and $\mathrm{b}$ ). Comet and colony formation assays further demonstrated that $\mathrm{H} 1.2 \mathrm{KO}$ cells exhibited increased repair activity and higher survival rates compared to wild-type, $\mathrm{H} 1.3$ or $\mathrm{H} 1.4 \mathrm{KO}$ cells (Fig. 7a, b; Supplementary information, Figure S6c and d). Interestingly, $\mathrm{H} 1.3$ and $\mathrm{H} 1.4 \mathrm{KO}$ cells showed moderately impaired cell survival compared to wild-type cells (Supplementary information, Figure S6d), suggesting that $\mathrm{H} 1$ variants may function differently in DNA repair. Similarly, stable H1.2 knockdown cells exhibited higher survival rates following etoposide treatment (Supplementary information, Figure S6e and f). In addition, stable over-expression of $\mathrm{H} 1.2$, but not $\mathrm{H} 1.3$ or $\mathrm{H} 1.4$, reduced the DNA repair efficiency (Supplementary information, Figure S6g). Overexpression of $\mathrm{H} 1.2$ also resulted in delayed removal of $\mathrm{\gamma}-\mathrm{H} 2 \mathrm{AX}$, an indicator of DNA repair (Supplementary information, Figure S6h). We also used DR-GFP and pEJ5-GFP U2OS cells to measure the efficiencies of HR and NHEJ pathways, the two major pathways for repair of DSBs. ${ }^{29}$ As expected, $\mathrm{H} 1.2 \mathrm{KO}$ led to an increase in both the HR and NHEJ efficiencies (Fig. 7c, d; Supplementary information, Figure S6i and j). Consistently, over-expression of $\mathrm{H} 1.2$, rather than other $\mathrm{H} 1$ isoforms resulted in a significant decrease in repair activity in DR-GFP cells (Supplementary information, Figure S6k).

Finally, we demonstrate that $\mathrm{H} 1.2$ displacement and PARylation are indispensable for ATM-dependent DNA repair and cell survival.
In accordance with the inhibitory role of $\mathrm{H} 1.2$ in the ATMdependent DNA damage response and repair, ATM KO cells exhibited poor repair efficiencies and decreased cell survival, which could not be reversed by H1.2 KO (Fig. 7e, f; Supplementary information, Figure S7a-c). Consistently, resistance to etoposide treatment induced by $\mathrm{H} 1.2$ knockdown was restored by ATM or PARP1 inhibition, but not by DNA-PK inhibition (Supplementary information, Figure S7d-f). More importantly, rescue experiments showed that enhanced DNA repair efficiency and resistance to DNA damage treatment in $\mathrm{H} 1.2 \mathrm{KO}$ cells were suppressed by the reintroduction of mutated $\mathrm{H} 1.2$ (S188A), whereas wild-type $\mathrm{H} 1.2$ exhibited a moderate detrimental effect (Fig. 7g, h; Supplementary information, Figure $\mathrm{S7g}$ ). In addition, reintroduction of either wildtype or mutated $\mathrm{H} 1.2$ could neither rescue nor aggravate impaired cell survival in ATM KO cells (Fig. 7h). Together, these results suggest that PARylation of $\mathrm{H} 1.2$ at $\mathrm{S} 188$ residue is indispensable for efficient DNA damage repair and cell survival.

\section{DISCUSSION}

Our data support a role for linker histone H1.2 in restraining ATM activity and protecting chromatin from aberrant ATM loading and activation. Upon DNA damage, H1.2 is PARylated and displaced from chromatin to permit full activation of ATM (Fig. 7i). We therefore propose a novel model whereby $\mathrm{H} 1.2$ functions as a molecular brake to ATM's binding to MRN and that DNA damageinduced ATM activation requires both assembly of the MRN complex and release of H1.2.

Structural changes of chromatin may dictate ATM activation, but the facts that ATM can be activated when chromatin is either compacted ( $\mathrm{NaCl}$ treatment) or decompacted (HDAC inhibitor treatment) suggest that additional factors are also involved in ATM activation. Various mechanisms have been reported to account for the regulation of ATM. For example, FoxO3a interacts with the FAT domain of ATM to regulate its dimerization and subsequent activation. ${ }^{30}$ The E3 ligases Chfr and RNF8 synergistically control histone ubiquitination and acetylation, leading to chromatin relaxation and ATM activation. ${ }^{31} \mathrm{~A}$ recent study found that DNAPKcs directly phosphorylates ATM at multiple sites and inhibits ATM activity. ${ }^{32}$ In this study, we show ATM interacts with $\mathrm{H} 1.2$ via a specific fragment of its HEAT repeat domain, which critically regulates the binding of ATM substrates and regulators. ${ }^{33-35}$ This provides a structural basis for the direct inhibition of ATM activity by H1.2. Mechanistically, we demonstrate that H1.2, as a critical component of the chromatin, competes with MRN for the binding of ATM, which leads to impaired ATM interaction with MRN or its substrates. The existence of $\mathrm{H} 1.2$ as an inhibitory factor of ATM activation is supported by the theory that the DNA damage response should be tightly checked and spatiotemporally regulated to ensure optimized DNA repair. ${ }^{36}$ Most importantly, we showed that ATM activation correlates with $\mathrm{H} 1.2$ destabilization upon the application of non-DNA-damaging stimuli, such as 
a

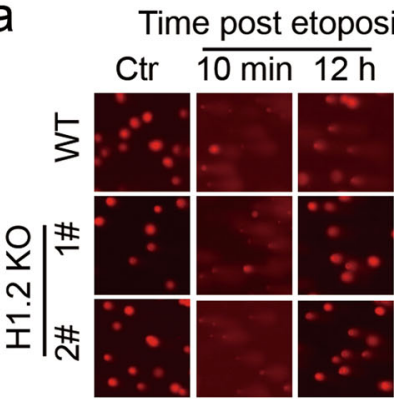

C

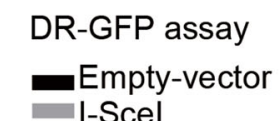

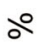

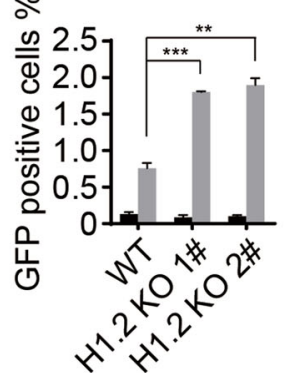

e

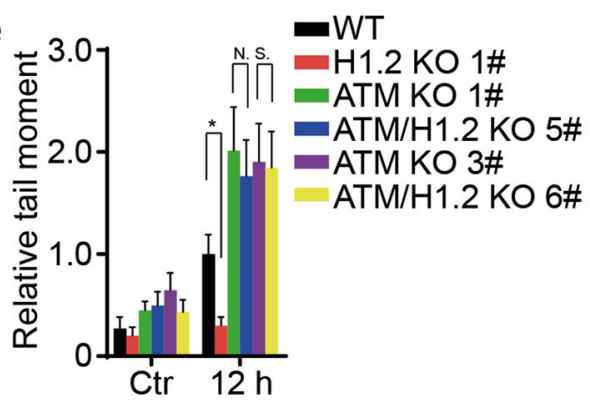

f

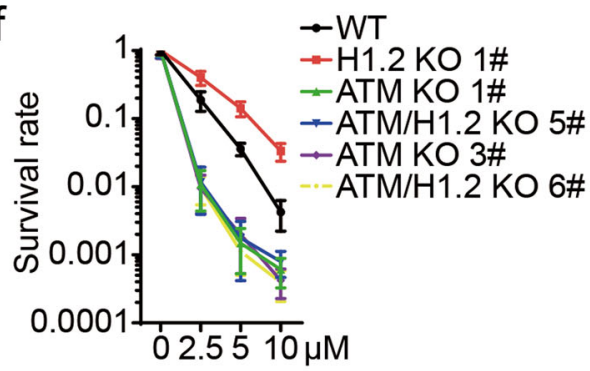

b

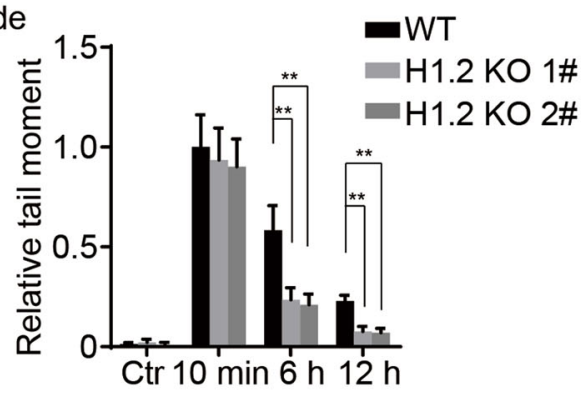

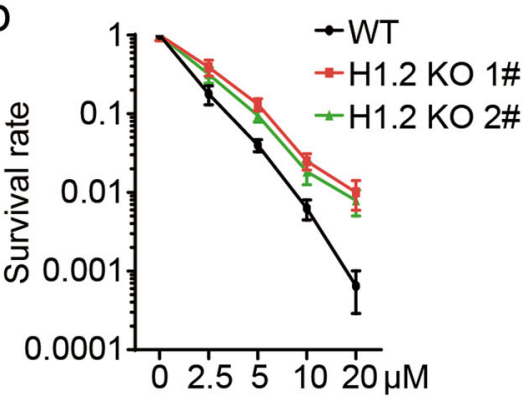

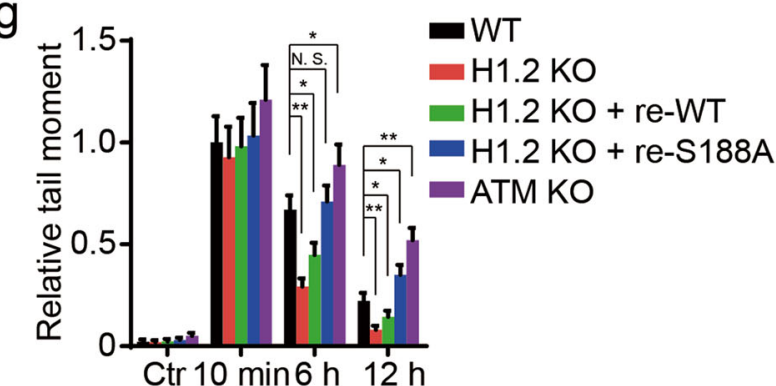

$\mathrm{h}$

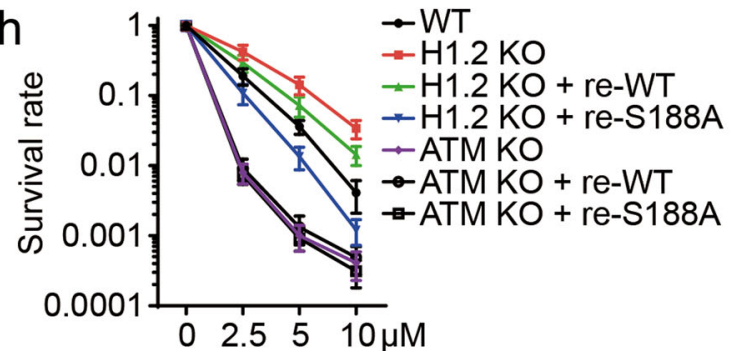

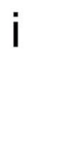

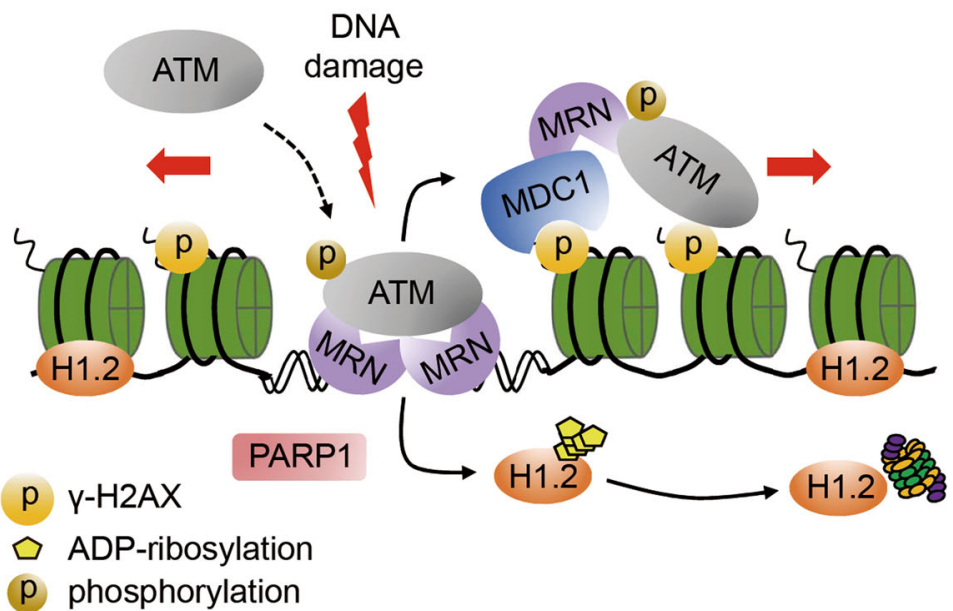

HDAC inhibitors and $\mathrm{NaCl}$. These results are supported by previous studies showing that the ATM-dependent DNA damage response can be activated without DNA breaks, for example, by persistent chromatin binding of DNA repair factors or local condensation of chromatin. 37,38

It is now well appreciated that MRN activates ATM via multiple mechanisms and the interaction between ATM and the MRN complex is essential for ATM's activation. ${ }^{39}$ The MRN complex is a bona fide sensor of DNA DSBs and amplifies ATM activation through a positive feedback loop. ${ }^{40-45}$ Here, we show that regulation of ATM by $\mathrm{H} 1.2$ is MRN-dependent. H1.2 associates with the MRN complex and inhibits MRN-dependent ATM activation without affecting the recruitment of MRN. This agrees with the earlier finding that localization of MRN to DNA damage sites is independent of ATM. ${ }^{46}$ These data also suggest that the previously reported ATM-dependent regulation of MRN recruitment may result in its relocalization to regions flanking DSBs. ATM can also be recruited and activated without DNA damage sensors, ${ }^{47,48}$ raising the possibility that $\mathrm{H} 1.2$ regulates the activation of ATM through other pathways. For example, it is recently reported that $\mathrm{H} 1.2$ inhibits $\mathrm{H} 4 \mathrm{~K} 16$ acetylation by promoting the expression of histone deacetylase SIRT1 and 
Fig. 7 Linker histone $\mathrm{H} 1.2$ dissociation and destabilization are required for DNA repair and cell survival. a, b Wild-type and H1.2 KO (1\# and 2\#) HeLa cells were analyzed by comet and colony formation assays. The tail moment of wild-type cells at 10 min post treatment was normalized to 1. The data represent the mean \pm SD. c Wild-type and H1.2 KO (1\# and 2\#) DR-GFP U2OS cells were analyzed by DR-GFP assay. The data represent the mean \pm SD. d Wild-type and H1.2 KO pEJ5-GFP U2OS cells were analyzed by EJ5-GFP assay. The data represent the mean \pm SD. e, f Wild-type, H1.2 KO (1\#), two ATM KO (1\# and 3\#) and two ATM/H1.2 double KO (5\# and 6\#) HeLa cells were analyzed by comet and colony formation assays. The tail moment of wild type cells at $12 \mathrm{~h}$ post treatment was normalized to 1 . The data represent the mean \pm SD. $\mathbf{g}, \mathbf{h}$ Wildtype, H1.2 KO (1\#), H1.2 KO (1\#) with reintroduced wild type or S188A mutated H1.2, and ATM KO (1\#) HeLa cells were analyzed by comet and colony formation assays. ATM KO (1\#) HeLa cells with reintroduced wild-type or S188A mutated H1.2 were also analyzed by colony formation assay. The tail moment of wild-type cells at 10 min post treatment was normalized to 1 . The data represent the mean \pm SD. i A schematic model for the dynamic regulation of ATM by H1.2. In the absence of DNA damage, H1.2 binds to the chromatin and blocks the interactions between ATM and MRN to prevent the recruitment and activation of ATM. Upon DNA damage, PARP1 is activated to PARylate and displace $\mathrm{H} 1.2$ from chromatin, whereby ATM is permitted to be recruited and activated by MRN and DNA breaks. Activated ATM, which is amplified by an ATM-MDC1-MRN positive feedback loop, drives the DNA damage response through phosphorylation of a wide spectrum of substrates, including $\mathrm{H} 2 \mathrm{AX}$

HDAC1. ${ }^{49}$ Since H4K16 acetylation has been demonstrated to be critical in regulating ATM activation, ${ }^{50}$ it is rational to speculate that $\mathrm{H} 1.2$ may also regulate ATM in this manner.

Chromatin structure and dynamics, for which linker histone $\mathrm{H} 1$ plays an essential role, are key factors in DNA repair and maintenance of genome integrity. ${ }^{51,52}$ However, how $\mathrm{H} 1$ participates in the DNA damage response and repair process remains elusive. We refined this concept and demonstrated the specific displacement and destabilization of linker histone H1.2 upon DNA damage. These findings further support the participation of both active recruitment and dissociation of signaling and repair factors in DNA damage-induced protein dynamics. ${ }^{53}$ Although $\mathrm{H} 1.2 \mathrm{KO}$ did not alter general chromatin structure or cell survival under unstressed conditions, our results, together with previous reports, show that deletion of $\mathrm{H} 1.2$ leads to cell cycle progression defects. $^{54}$ This suggests that H1.2 may harbor critical functions in undamaged cells. Data derived from Drosophila models showed that $\mathrm{H} 1$ counters genome instability through inhibition of R-loop formation. ${ }^{6}$ This is in accord with our data that $\mathrm{H} 1.2$ potently inhibits ATM activation, because R-loops are known to activate ATM. ${ }^{22} \mathrm{H} 1$ has been proposed to amplify DNA damage-induced ubiquitin signaling through RNF8-dependent ubiquitination and promote DNA repair, although a very recent study disputes the role of $\mathrm{H} 1$ and suggests that L3MBTL2 is required to amplify RNF8/ RNF168-mediated ubiquitin signals. ${ }^{9,55}$ Hence it is possible that different $\mathrm{H} 1$ variants may function distinctly at different stages of the DNA damage response and repair. An example of this functional discrepancy is that $\mathrm{H} 1.2$ specifically regulates DSBinduced apoptosis, whereas $\mathrm{H} 1.3$ and $\mathrm{H} 1.4$ cannot. $^{11}$ Together with these reports, our findings point to previously underestimated functions of $\mathrm{H} 1$ in DNA damage repair.

PARP1 is among the first proteins to respond to DNA damage, and its function in both SSB and DSB repair has been extensively characterized. ${ }^{56}$ Deletion or inhibition of PARP1 results in hypersensitivity to DNA damage inducers and compromised ATM activation. ${ }^{19,57,58}$ PARP1 modifies a set of proteins via the addition of ADP-ribose moieties to its substrates to alter protein-protein or protein-DNA interactions. ${ }^{59}$ In the present study, we found that DNA damage-induced H1.2 dynamics were regulated via PARylation of its $C$ terminus. PARylation, unlike other post-translational modifications, is an immediate response to DNA damage, as PARP1 is activated within the first seconds of detecting damage. ${ }^{53}$ These data are in agreement with our proposal that $\mathrm{H} 1.2$ displacement precedes ATM activation, suggesting that $\mathrm{H} 1$ PARylation is a unique modification that regulates ATM activation and the DNA damage response. $\mathrm{H} 1$ is known to undergo various modifications upon DNA damage, including rapid dephosphorylation by the protein phosphatases PP1/PP2A, phosphorylation by DNA-PKCs and ubiquitination by RNF8/RNF168 following DNA damage treatment. ${ }^{9,60,61}$ Although we did not observe a functional relevance of these $\mathrm{H} 1$ posttranslational modifications in ATM activation, PARylation of $\mathrm{H} 1$ may crosstalk with other modifications, which will be an interesting topic for future study.

Our present study has provided novel insight into the essential role of linker histone $\mathrm{H} 1.2$ destabilization in ATM activation and DNA damage repair. Further investigations into the chromatin perturbation that controls ATM activation are now warranted. Our identification of linker histone $\mathrm{H} 1.2$ as a novel PARP1 downstream target may help us better understand the functional mechanisms of ATM inhibition in cancer treatment and may lead to the discovery of new promising targets for cancer therapy.

\section{MATERIALS AND METHODS}

Cell culture, antibodies and reagents

HeLa, HCT116, HEK293T and U2OS cells were purchased from American Type Culture Collection (ATCC). NBS1 KO HeLa cells were kindly provided by Dr. Junjie Chen (MD Anderson Cancer Center, USA). Cells were cultured in DMEM or McCoy's 5A medium supplemented with $10 \%$ ( $\mathrm{vol} / \mathrm{vol})$ fetal bovine serum and $1 \%$ penicillin/streptomycin according to ATCC guidelines and maintained in a $37^{\circ} \mathrm{C}$ incubator with a humidified, $5 \% \mathrm{CO}_{2}$ atmosphere. The antibodies used in this study include: anti-ATM (GeneTex, GTX70103), anti-H1.2 (GeneTex, GTX122561), anti-GFP (MBL, M048-3), anti-HIS (MBL, PM032), anti-HA (MBL, M180-3), antiFLAG (Sigma-Aldrich, F3165), anti-GST (APPLYGEN, C1303), antiphospho-ATM (S1981; Cell Signaling, 5883), anti-phospho-NBS1 (S343; Cell Signaling, 3001), anti-phospho-SMC1 (S957; Cell Signaling, 58052), anti-SMC1 (Cell Signaling, 4802), anti-phosphoCHK2 (T68; Cell Signaling, 2197), anti-CHK2 (Cell Signaling, 3440), anti-phospho-p53 (S15; Cell Signaling, 9286), anti-phospho-H2AX (S139; Cell Signaling, 9718), anti-H2AX (Cell Signaling, 2595), antiPARP1 (Cell Signaling, 9532), anti-GAPDH (Santa Cruz, sc-32233), anti-ATR (Santa Cruz, sc-1887), anti-DNA-PKcs (Santa Cruz, sc1552), anti-NBS1 (Santa Cruz, sc-8580), anti-p53 (Santa Cruz, sc126), anti-H1.4 (Santa Cruz, sc-34464), anti-cyclin E (Santa Cruz, sc247), anti-H1.2 (for IP and ChIP; Abcam, ab17677), anti-H1.3 (Abcam, ab24174), anti-H3 (Abcam, ab1791), anti-H4 (Abcam, ab10158), anti-RAD50 (Abcam, ab89), anti-MRE11 (Abcam, ab12159), anti-phospho-H3 (S10; Abcam, ab5176), anti-ace-H3 (Active Motif, 39139), anti-H1 (Active Motif, 39707), anti-PAR (Trevigen, 4335-MC-100). Etoposide, adriamycin, cisplatin, hydroxyurea, oxaliplatin, thymidine, chloroquine $(\mathrm{CHQ})$, Leptomycin $B$ (LMB) and G418 were purchased from Sigma-Aldrich, and all other inhibitors, including Ku55933, Ku57788, PJ34, Oprozomib and MG132, were purchased from Selleckchem, USA.

Plasmids

All plasmids were transfected with Lipofectamine 2000 (Life Technologies-Invitrogen, USA) according to the manufacturer's instructions. $\mathrm{H} 1.2, \mathrm{H} 1.3$ and $\mathrm{H} 1.4$ cDNAs were amplified and cloned into the p3x FLAG-CMV-10 vector (Addgene, USA). Fulllength $\mathrm{H} 1.2$ and various fragments ( $\mathrm{N}$-terminal domain, 1-35 aa; 
globular domain, 36-112 aa; C-terminal domain, 113-213 aa; $\Delta C 1$, 1-179 aa; $\Delta C 2,1-112+180-213$ aa; $\Delta C, 1-112$ aa) were cloned into the pEGFP-C2, pGEX-4T3 or pET28a vectors (Addgene, USA). The full-length FLAG-ATM expression construct was purchased from Addgene, USA. GST-ATM fragments (F1, 1-247 aa; F2, 250-522 aa; F3, 523-769 aa; F4, 722-1102 aa; F5, 1098-1371 aa; F6, 1245-1435 aa; F7, 1239-1770 aa; F8, 1764-2138 aa; F9, 2141-2428 aa; F10, 2427-2841 aa; F11, 2842-3056 aa; F12, 2682-3012 aa) were provided by Dr. Fabrizio d'Adda di Fagagna (FIRC Institute of Molecular Oncology Foundation, Italy). Site-specific mutations of H1.2 (T126/146/165A, T126/146/165E, E115A, S173A, S188A) were generated using a site-directed mutagenesis kit (Vazyme, China).

\section{CRISPR-Cas9 based gene-editing}

$\mathrm{H} 1$ variant-specific KO HeLa cells were generated via Lipofectamine 2000 transfection of sgRNA constructs in a px459/Puro vector (Addgene, USA), as previously described. ${ }^{62}$ The sgRNA sequences targeted H1.2 (sequence 1: GGTACGCCTCGTAAGGC GTC, sequence 2: GGCTGGGGGTACGCCTCGTA), H1.3 (sequence 1: CGCAAGCGCTITCTTAAGCG, sequence 2: GGTGTIIITCTGCGGGT GC), H1.4 (sequence 1: TTCACGGGAGTCTTCTCGGC, sequence 2: GCGGCCAAGCGCAAAGCGTC) and ATM (sequence 1: CTCTATC ATGTTCTAGTTGA, sequence 2: TTGTTTCAGGATCTCGAATC, sequence 3: CGGCATTCAGATTCCAAACA).

\section{Chromatin fractionation}

Cells were harvested into buffer I (50 mM HEPES pH 7.5, $150 \mathrm{mM}$ $\mathrm{NaCl}$ and $1 \mathrm{mM}$ EDTA) supplemented with $0.1 \%$ Triton X-100, 1\% protease inhibitor cocktail (Roche Holding AG, Switzerland) and 2 $\mu \mathrm{M}$ PMSF and lysed on ice for $3 \mathrm{~min}$. The supernatant was discarded and the pellet dissolved in buffer I supplemented with $200 \mu \mathrm{g} / \mathrm{mL}$ RNaseA and $1 \%$ protease inhibitor cocktail and incubated at room temperature for $30 \mathrm{~min}$. The supernatant was discarded after centrifugation and the pellet was resuspended in buffer I, boiled in an equal volume of $2 \times$ SDS/PAGE sample buffer at $100{ }^{\circ} \mathrm{C}$ for $5 \mathrm{~min}$ and subjected to immunoblotting.

\section{Immunoprecipitation assay}

Cells were harvested and lysed in NP-40 buffer $(20 \mathrm{mM}$ Tris. $\mathrm{HCl}$ pH 8.0, $137 \mathrm{mM} \mathrm{NaCl}, 1 \%$ NP-40, $10 \%$ glycerol, $2 \mathrm{mM}$ EDTA, $1 \%$ protease inhibitor cocktail) for $30 \mathrm{~min}$ at $4{ }^{\circ} \mathrm{C}$. After centrifugation, the supernatant was incubated with the indicated antibodies and protein G or A Sepharose slurry (GE Healthcare, USA) at $4{ }^{\circ} \mathrm{C}$ rotating overnight. For benzonase treatment, the supernatant was treated with benzonase (Millipore, USA) at $10 \mathrm{U} / \mathrm{mL}$ at $4{ }^{\circ} \mathrm{C}$ while rotating for $2 \mathrm{~h}$ before incubating with the antibodies. The beads were then washed and analyzed by immunoblotting.

\section{GST pull-down}

GST or GST-tagged plasmids were transformed into Escherichia coli BL21 cells (TianGen, China) and induced with $0.1 \mathrm{mM}$ IPTG (SigmaAldrich, USA) overnight at $28^{\circ} \mathrm{C}$ and then purified using glutathione-Sepharose 4B beads (GE Healthcare, USA). HIS-tagged plasmids were transformed and induced in the same way, but purified using HIS agarose beads. Equal amounts of individual HISfusion protein were incubated with GST-fusion proteins (from E. coli) in TEN buffer (10 mM Tris. $\mathrm{HCl}$ pH 8.0, 1 mM EDTA, $100 \mathrm{mM} \mathrm{NaCl}$ ) for $4 \mathrm{~h}$ at $4{ }^{\circ} \mathrm{C}$. The samples were then washed three times in TEN buffer by centrifugation at $94 \times g$ at $4{ }^{\circ} \mathrm{C}$ for $1 \mathrm{~min}$ and the precipitated components were analyzed by immunoblotting.

In vitro phosphorylation assay

Full-length ATM and ATR plasmids were transfected into HEK293T cells and the ATM or ATR proteins were immunoprecipitated using FLAG-conjugated M2 agarose beads $48 \mathrm{~h}$ after transfection. Beads were first washed with lysis buffer (without NP40) and then twice in kinase buffer $(10 \mathrm{mM}$ Tris. $\mathrm{HCl} \mathrm{pH} 7.4,150$ $\mathrm{mM} \mathrm{NaCl}, 10 \mathrm{mM} \mathrm{MgCl}_{2}, 0.5 \mathrm{mM}$ DTT) before elution with the
FLAG peptide. The eluents were added to kinase buffer and incubated with different substrates and purified proteins. The reaction was initiated by adding $30 \mu \mathrm{M}$ ATP (final concentration), and incubated at $30^{\circ} \mathrm{C}$ for $1 \mathrm{~h}$. The samples were subjected to CBB staining or immunoblotting after adding $5 \times$ SDS/PAGE sample buffer and boiling at $100^{\circ} \mathrm{C}$ for $5 \mathrm{~min}$.

\section{In vitro PARylation assay}

$\mathrm{HIS}-\mathrm{H} 1.2$ was subjected to in vitro PARylation at room temperature for $30 \mathrm{~min}$ or the indicated time in a reaction buffer $(50 \mathrm{mM}$ Tris. $\mathrm{HCl} \mathrm{pH} \mathrm{8,} 25 \mathrm{mM} \mathrm{MgCl}$, $50 \mathrm{mM} \mathrm{NaCl}$ ) supplemented with 200 $\mu \mathrm{M} \mathrm{NAD}{ }^{+}$, activated DNA and PARP1 enzyme (Thermo Fisher, or immunoprecipitated from HET293T cells). The reaction was stopped by adding $5 \times$ SDS/PAGE sample buffer and the samples were analyzed by immunoblotting.

Laser micro-irradiation-coupled live-cell imaging Laser micro-irradiation was performed as previously descried. ${ }^{63}$ Briefly, cells were grown on a glass-bottomed dish and locally irradiated with a $365 \mathrm{~nm}$ pulsed nitrogen UV laser $(16 \mathrm{~Hz}$ pulse, $41 \%$ laser output) generated from a micropoint system (Andor). This system was directly coupled to the epifluorescence path of the Nikon A1 confocal imaging system and time-lapse images were captured every $10 \mathrm{~s}$ for the indicated time. Signal intensity of the irradiation path from more than 50 cells was calculated using an ImageJ software (version 1.51j8).

Immunofluorescence

Cells were fixed with $4 \%$ paraformaldehyde and permeabilized with $0.1 \%$ Triton X-100, followed by blocking with $1 \%$ BSA. For in situ detergent extraction, cells were lysed in the dish in buffer I ( $50 \mathrm{mM}$ HEPES pH 7.5, $150 \mathrm{mM} \mathrm{NaCl}$ and $1 \mathrm{mM}$ EDTA) supplemented with $0.1 \%$ Triton X-100 for 10 min on ice before fixation. The cells were then incubated with the indicated primary antibodies at $4{ }^{\circ} \mathrm{C}$ overnight. After being washed three times with $1 \%$ BSA, the slides were exposed to a FITC/TRITC-conjugated secondary antibody for $2 \mathrm{~h}$ at room temperature in the dark and then washed three times with blocking buffer. The samples were then embedded in DAPI and observed under an Olympus FV1000IX81 confocal microscope. About 200 cells were analyzed for quantification and the experiments were repeated independently for at least three times.

\section{Comet assay}

Comet assays were performed as previously described. ${ }^{64}$ Briefly, cells were treated with $40 \mu \mathrm{M}$ etoposide for $2 \mathrm{~h}$ and released for the indicated time. The collected cells were then mixed gently with pre-melted low-temperature-melting agarose at a volume ratio of 1:1 (v/v) and spread on glass slides. The slides were then submerged in pre-cooled lysis buffer at $4^{\circ} \mathrm{C}$ for $90 \mathrm{~min}$. After rinsing, the slides were subjected to electrophoresis at $1.0 \mathrm{~V} / \mathrm{cm}$ for $20 \mathrm{~min}$, and then stained with propidium iodide (PI). Fluorescent images of $\geq 100$ nuclei were captured under an Olympus FV1000-IX81 Confocal Microscope (Tokyo, Japan). The images were analyzed for tail moment using CASP (Comet Assay Software Project) version 1.2.2. Quantification of tail moment was calculated by measuring the tail length and amount of DNA (quantified by PI intensity) in the tail.

\section{DR-GFP assay and EJ5-GFP assay}

DR-GFP or pEJ5-GFP U2OS cells with a single copy of DR-GFP in a random locus were transfected with $\mathrm{HA}-\mathrm{I}-\mathrm{Scel}$ and other indicated plasmids $24 \mathrm{~h}$ before HA-I-Scel transfection if necessary. Cells were harvested $48 \mathrm{~h}$ after HA-I-Scel transfection and subjected to flow cytometric analysis. The percentage of GFP-positive cells, which indicated HR-mediated or NHEJ-mediated DSB repair efficiency, was determined. The mean values were obtained from three independent experiments. 
Colony formation assay

Cells were seeded in six-well plates and after $24 \mathrm{~h}$, were exposed to etoposide at the indicated concentrations for $2 \mathrm{~h}$ (in some cases inhibitors were added $1 \mathrm{~h}$ prior to etoposide treatment). The cells were then washed three times with serum-free medium and then re-cultured in fresh medium. After approximately 10 days culture under normal conditions, cell colonies were visualized by crystal violet staining and colonies consisting of $>50$ cells were counted.

\section{Statistics}

Data were analyzed by Student's $t$ test. A $p<0.05$ was considered statistically significant (N.S., $p>0.05,{ }^{*} p<0.05$, $\left.{ }^{* *} p<0.01,{ }^{* *} p<0.001\right)$. Three or more independent experiments were performed in all cases. The data represent the mean $\pm S D$. Other materials and methods are described in Supplementary information, Data S1.

\section{ACKNOWLEDGEMENTS}

The authors are grateful to Dr. Tanya Paull (University of Texas, USA) and Dr. Fabrizio d'Adda di Fagagna (FIRC Institute of Molecular Oncology Foundation, Italy) for kindly providing the ATM plasmids; to Dr. Junjie Chen (MD Anderson Cancer Center, USA) for kindly providing NBS1 KO HeLa cells and to Dr. Jessica Tamanini for editing the manuscript prior to submission. This study was supported by the National Key R\&D Program of China (grant number 2017YFA0503900) and the National Natural Science Foundation of China (grant numbers 81621063, 81530074, 31570812 and 81720108027), and the Shenzhen Municipal Commission of Science and Technology Innovation (grant numbers JCYJ20160427104855100 and JCYJ20170818092450901).

\section{AUTHOR CONTRIBUTIONS}

Z.L. and Y.L. performed most of the experimental work. M.T. contributed to construction and extraction of plasmids. B.P. and X.X. helped with the laser microirradiation assays. X.L., Q.Y. and Q.Z. assisted in protein purification and in vitro assays. T.H and M.L. performed immunofluorescence experiments. C.L. and L.W. helped with generation of knockout cell lines. Y.Z., H.W. and Y.Y. helped in the design of some experiments. W.-G.Z. supervised the project, and Z.L. and W.-G.Z. wrote the manuscript.

\section{ADDITIONAL INFORMATION}

Supplementary information accompanies this paper at https://doi.org/10.1038/ s41422-018-0048-0.

Competing interests: The authors declare no competing interests.

Publisher's note: Springer Nature remains neutral with regard to jurisdictional claims in published maps and institutional affiliations

\section{REFERENCES}

1. Misteli, T., Gunjan, A., Hock, R., Bustin, M. \& Brown, D. T. Dynamic binding of histone $\mathrm{H} 1$ to chromatin in living cells. Nature 408, 877-881 (2000).

2. Lever, M. A., Th'ng, J. P., Sun, X. \& Hendzel, M. J. Rapid exchange of histone H1.1 on chromatin in living human cells. Nature 408, 873-876 (2000).

3. Shen, X., Yu, L., Weir, J. W. \& Gorovsky, M. A. Linker histones are not essential and affect chromatin condensation in vivo. Cell 82, 47-56 (1995).

4. Fan, Y., Sirotkin, A., Russell, R. G., Ayala, J. \& Skoultchi, A. I. Individual somatic $\mathrm{H} 1$ subtypes are dispensable for mouse development even in mice lacking the H1(0) replacement subtype. Mol. Cell Biol. 21, 7933-7943 (2001).

5. Fan, $\mathrm{Y}$. et al. Histone $\mathrm{H} 1$ depletion in mammals alters global chromatin structure but causes specific changes in gene regulation. Cell 123, 1199-1212 (2005).

6. Bayona-Feliu, A., Casas-Lamesa, A., Reina, O., Bernues, J. \& Azorin, F. Linker histone $\mathrm{H} 1$ prevents R-loop accumulation and genome instability in heterochromatin. Nat. Commun. 8, 283 (2017).

7. Downs, J. A., Kosmidou, E., Morgan, A. \& Jackson, S. P. Suppression of homologous recombination by the Saccharomyces cerevisiae linker histone. Mol. Cell 11, 1685-1692 (2003).

8. Murga, M. et al. Global chromatin compaction limits the strength of the DNA damage response. J. Cell Biol. 178, 1101-1108 (2007).
9. Thorslund, $\mathrm{T}$. et al. Histone $\mathrm{H} 1$ couples initiation and amplification of ubiquitin signalling after DNA damage. Nature 527, 389-393 (2015).

10. Rosidi, B. et al. Histone $\mathrm{H} 1$ functions as a stimulatory factor in backup pathways of NHEJ. Nucleic Acids Res. 36, 1610-1623 (2008).

11. Konishi, A. et al. Involvement of histone H1.2 in apoptosis induced by DNA double-strand breaks. Cell 114, 673-688 (2003).

12. Millan-Arino, L. et al. Mapping of six somatic linker histone $H 1$ variants in human breast cancer cells uncovers specific features of H1.2. Nucleic Acids Res. 42, 4474-4493 (2014).

13. Bakkenist, C. J. \& Kastan, M. B. DNA damage activates ATM through intermolecular autophosphorylation and dimer dissociation. Nature 421, 499-506 (2003).

14. Lee, J. H. \& Paull, T. T. Direct activation of the ATM protein kinase by the Mre11/ Rad50/Nbs1 complex. Science 304, 93-96 (2004).

15. Sun, Y., Jiang, X., Chen, S., Fernandes, N. \& Price, B. D. A role for the Tip60 histone acetyltransferase in the acetylation and activation of ATM. Proc. Natl. Acad. Sci. USA 102, 13182-13187 (2005).

16. Lee, J. H. \& Paull, T. T. ATM activation by DNA double-strand breaks through the Mre11-Rad50-Nbs1 complex. Science 308, 551-554 (2005).

17. Dupre, A., Boyer-Chatenet, L. \& Gautier, J. Two-step activation of ATM by DNA and the Mre11-Rad50-Nbs1 complex. Nat. Struct. Mol. Biol. 13, 451-457 (2006).

18. You, Z., Bailis, J. M., Johnson, S. A., Dilworth, S. M. \& Hunter, T. Rapid activation of ATM on DNA flanking double-strand breaks. Nat. Cell Biol. 9, 1311-1318 (2007).

19. Haince, J. F. et al. Ataxia telangiectasia mutated (ATM) signaling network is modulated by a novel poly(ADP-ribose)-dependent pathway in the early response to DNA-damaging agents. J. Biol. Chem. 282, 16441-16453 (2007).

20. Kim, Y. C. et al. Activation of ATM depends on chromatin interactions occurring before induction of DNA damage. Nat. Cell Biol. 11, 92-96 (2009).

21. Kaidi, A. \& Jackson, S. P. KAT5 tyrosine phosphorylation couples chromatin sensing to ATM signalling. Nature 498, 70-74 (2013).

22. Tresini, M. et al. The core spliceosome as target and effector of non-canonical ATM signalling. Nature 523, 53-58 (2015).

23. Blackford, A. N. \& Jackson, S. P. ATM, ATR, and DNA-PK: the trinity at the heart of the DNA damage response. Mol. Cell 66, 801-817 (2017).

24. Stiff, T. et al. ATM and DNA-PK function redundantly to phosphorylate $\mathrm{H} 2 \mathrm{AX}$ after exposure to ionizing radiation. Cancer Res. 64, 2390-2396 (2004).

25. Falck, J., Coates, J. \& Jackson, S. P. Conserved modes of recruitment of ATM, ATR and DNA-PKcs to sites of DNA damage. Nature 434, 605-611 (2005).

26. Catez, F., Ueda, T. \& Bustin, M. Determinants of histone H1 mobility and chromatin binding in living cells. Nat. Struct. Mol. Biol. 13, 305-310 (2006).

27. Messner, S. \& Hottiger, M. O. Histone ADP-ribosylation in DNA repair, replication and transcription. Trends Cell Biol. 21, 534-542 (2011).

28. Leidecker, $O$. et al. Serine is a new target residue for endogenous ADP ribosylation on histones. Nat. Chem. Biol. 12, 998-1000 (2016).

29. Sancar, A., Lindsey-Boltz, L. A., Unsal-Kacmaz, K. \& Linn, S. Molecular mechanisms of mammalian DNA repair and the DNA damage checkpoints. Annu. Rev. Biochem. 73, 39-85 (2004).

30. Tsai, W. B., Chung, Y. M., Takahashi, Y., Xu, Z. \& Hu, M. C. Functional interaction between FOXO3a and ATM regulates DNA damage response. Nat. Cell Biol. 10, 460-467 (2008).

31. Wu, J. et al. Chfr and RNF8 synergistically regulate ATM activation. Nat. Struct. Mol. Biol. 18, 761-768 (2011).

32. Zhou, Y. et al. Regulation of the DNA damage response by DNA-PKcs inhibitory phosphorylation of ATM. Mol. Cell 65, 91-104 (2017).

33. You, Z., Chahwan, C., Bailis, J., Hunter, T. \& Russell, P. ATM activation and its recruitment to damaged DNA require binding to the $\mathrm{C}$ terminus of Nbs1. Mol. Cell Biol. 25, 5363-5379 (2005).

34. Wang, X. et al. Structure of the intact ATM/Tel1 kinase. Nat. Commun. 7, 11655 (2016).

35. Baretic, D. et al. Structures of closed and open conformations of dimeric human ATM. Sci. Adv. 3, e1700933 (2017).

36. Ciccia, A. \& Elledge, S. J. The DNA damage response: making it safe to play with knives. Mol. Cell 40, 179-204 (2010).

37. Soutoglou, E. \& Misteli, T. Activation of the cellular DNA damage response in the absence of DNA lesions. Science 320, 1507-1510 (2008).

38. Burgess, R. C., Burman, B., Kruhlak, M. J. \& Misteli, T. Activation of DNA damage response signaling by condensed chromatin. Cell Rep. 9, 1703-1717 (2014).

39. Stracker, T. H. \& Petrini, J. H. The MRE11 complex: starting from the ends. Nat. Rev. Mol. Cell Biol. 12, 90-103 (2011).

40. Carney, J. P. et al. The hMre11/hRad50 protein complex and Nijmegen breakage syndrome: linkage of double-strand break repair to the cellular DNA damage response. Cell 93, 477-486 (1998).

41. Goldberg, M. et al. MDC1 is required for the intra-S-phase DNA damage checkpoint. Nature 421, 952-956 (2003). 
42. Lou, Z., Minter-Dykhouse, K., Wu, X. \& Chen, J. MDC1 is coupled to activated CHK2 in mammalian DNA damage response pathways. Nature 421, 957-961 (2003).

43. Stewart, G. S., Wang, B., Bignell, C. R., Taylor, A. M. \& Elledge, S. J. MDC1 is a mediator of the mammalian DNA damage checkpoint. Nature 421, 961-966 (2003).

44. Stucki, M. et al. MDC1 directly binds phosphorylated histone $H 2 A X$ to regulate cellular responses to DNA double-strand breaks. Cell 123, 1213-1226 (2005).

45. Lou, Z. et al. MDC1 maintains genomic stability by participating in the amplification of ATM-dependent DNA damage signals. Mol. Cell 21, 187-200 (2006).

46. Mirzoeva, O. K. \& Petrini, J. H. DNA damage-dependent nuclear dynamics of the Mre11 complex. Mol. Cell Biol. 21, 281-288 (2001).

47. Guo, Z., Kozlov, S., Lavin, M. F., Person, M. D. \& Paull, T. T. ATM activation by oxidative stress. Science 330, 517-521 (2010).

48. Hartlerode, A. J., Morgan, M. J., Wu, Y., Buis, J. \& Ferguson, D. O. Recruitment and activation of the ATM kinase in the absence of DNA-damage sensors. Nat. Struct. Mol. Biol. 22, 736-743 (2015).

49. Wang, W. et al. Histone $\mathrm{HIST} 1 \mathrm{H} 1 \mathrm{C} / \mathrm{H} 1.2$ regulates autophagy in the development of diabetic retinopathy. Autophagy 13, 941-954 (2017).

50. Gupta, A. et al. Involvement of human MOF in ATM function. Mol. Cell Biol. 25, 5292-5305 (2005)

51. Misteli, T. \& Soutoglou, E. The emerging role of nuclear architecture in DNA repair and genome maintenance. Nat. Rev. Mol. Cell Biol. 10, 243-254 (2009).

52. Papamichos-Chronakis, M. \& Peterson, C. L. Chromatin and the genome integrity network. Nat. Rev. Genet. 14, 62-75 (2013).

53. Polo, S. E. \& Jackson, S. P. Dynamics of DNA damage response proteins at DNA breaks: a focus on protein modifications. Gene Dev. 25, 409-433 (2011).

54. Sancho, M., Diani, E., Beato, M. \& Jordan, A. Depletion of human histone H1 variants uncovers specific roles in gene expression and cell growth. PLoS Genet. 4 e1000227 (2008)

55. Nowsheen, S. et al. L3MBTL2 orchestrates ubiquitin signalling by dictating the sequential recruitment of RNF8 and RNF168 after DNA damage. Nat. Cell Biol. 20, 455-464 (2018).

56. Ray Chaudhuri, A. \& Nussenzweig, A. The multifaceted roles of PARP1 in DNA repair and chromatin remodelling. Nat. Rev. Mol. Cell Biol. 18, 610-621 (2017).
57. de Murcia, J. M. et al. Requirement of poly(ADP-ribose) polymerase in recovery from DNA damage in mice and in cells. Proc. Natl. Acad. Sci. USA 94, 7303-7307 (1997).

58. Bryant, H. E. et al. Specific killing of BRCA2-deficient tumours with inhibitors of poly(ADP-ribose) polymerase. Nature 434, 913-917 (2005).

59. Jungmichel, $\mathrm{S}$. et al. Proteome-wide identification of poly(ADP-Ribosyl)ation targets in different genotoxic stress responses. Mol. Cell 52, 272-285 (2013).

60. Guo, C. Y., Wang, Y., Brautigan, D. L. \& Larner, J. M. Histone H1 dephosphorylation is mediated through a radiation-induced signal transduction pathway dependent on ATM. J. Biol. Chem. 274, 18715-18720 (1999).

61. Kim, K. et al. Functional interplay between p53 acetylation and H1.2 phosphorylation in p53-regulated transcription. Oncogene 31, 4290-4301 (2012).

62. Ran, F. A. et al. Genome engineering using the CRISPR-Cas9 system. Nat. Protoc. 8 , 2281-2308 (2013).

63. Yang, Q. et al. G9a coordinates with the RPA complex to promote DNA damage repair and cell survival. Proc. Natl. Acad. Sci. USA 114, E6054-E6063 (2017).

64. Liao, W. J., McNutt, M. A. \& Zhu, W. G. The comet assay: a sensitive method for detecting DNA damage in individual cells. Methods 48, 46-53 (2009).

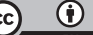

Open Access This article is licensed under. Creative Commons Attribution 4.0 International License, which permits use, sharing, adaptation, distribution and reproduction in any medium or format, as long as you give appropriate credit to the original author(s) and the source, provide. link to the Creative Commons license, and indicate if changes were made. The images or other third party material in this article are included in the article's Creative Commons license, unless indicated otherwise in. credit line to the material. If material is not included in the article's Creative Commons license and your intended use is not permitted by statutory regulation or exceeds the permitted use, you will need to obtain permission directly from the copyright holder. To view. copy of this license, visit http://creativecommons. org/licenses/by/4.0/.

(c) The Author(s) 2018 